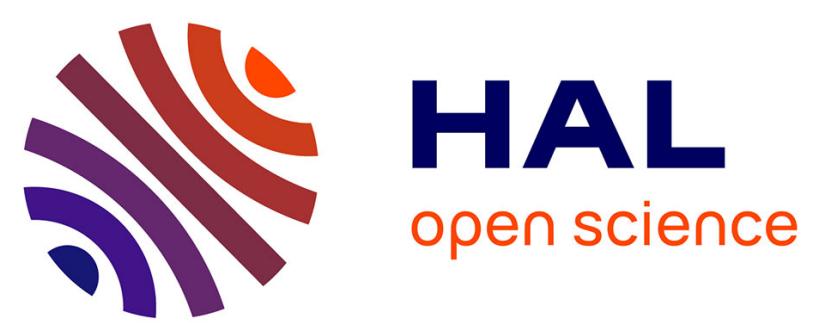

\title{
The production of clean diesel fuel by facile sun light photocatalytic desulfurization process using Cd-based diacetate as a novel liquid photocatalyst
}

Asmaa Morshedy, Sahar Tawfik, Karam Hashem, Dina Abd El-Aty, Ahmed Galhoum, Mohsen Mostafa, Eric Guibal

\section{To cite this version:}

Asmaa Morshedy, Sahar Tawfik, Karam Hashem, Dina Abd El-Aty, Ahmed Galhoum, et al.. The production of clean diesel fuel by facile sun light photocatalytic desulfurization process using Cdbased diacetate as a novel liquid photocatalyst. Journal of Cleaner Production, 2021, 279, pp.123629. 10.1016/j.jclepro.2020.123629 . hal-02921249

\section{HAL Id: hal-02921249 \\ https://hal.mines-ales.fr/hal-02921249}

Submitted on 25 Aug 2020

HAL is a multi-disciplinary open access archive for the deposit and dissemination of scientific research documents, whether they are published or not. The documents may come from teaching and research institutions in France or abroad, or from public or private research centers.
L'archive ouverte pluridisciplinaire HAL, est destinée au dépôt et à la diffusion de documents scientifiques de niveau recherche, publiés ou non, émanant des établissements d'enseignement et de recherche français ou étrangers, des laboratoires publics ou privés. 


\title{
The production of clean diesel fuel by facile sun light photocatalytic desulfurization process using Cd-based diacetate as a novel liquid photocatalyst
}

\author{
Asmaa S. Morshedy ${ }^{\text {a, * }}$, Sahar M. Tawfik ${ }^{a}$, Karam M. Hashem ${ }^{\text {a }}$, Dina M. Abd El-Aty ${ }^{\text {, }}$, Ahmed A. Galhoum \\ ${ }^{\mathrm{b}}$, Mohsen S. Mostafa ${ }^{\mathrm{a}}$, Eric Guibal ${ }^{\mathrm{c}, * *}$ \\ ${ }^{a}$ Refining Division, Egyptian Petroleum Research Institute, Nasr City, Cairo, 11727, Egypt \\ ${ }^{\mathrm{b}}$ Nuclear Materials Authority, P.O. Box 530, El-Maadi, Cairo, Egypt \\ ${ }^{\mathrm{c}}$ IMT - Mines Alès, Polymers, Composites \& Hybrids, 6 Avenue de Clavières, F-30319, Alès Cedex, France
}

\section{A B S T R A C T}

\begin{abstract}
Photocatalysis is one of the promising processes for developing greener fuels. This work compares a new liquid Cd-based diacetate and CdOx nanoparticles for photo-desulfurization of diesel. Various tools, including XRD, XPS, TEM, ${ }^{1} \mathrm{H} \&{ }^{13} \mathrm{C}$ NMR, FTIR, reflectance, and photoluminescence, were used for char-acterizing the materials. Different parameters, such as irradiation type, catalyst dosage, oxidizing agents, and solvent extraction were applied. The results showed that, under visible light irradiation with a linear halogen lamp (LHL), Cd diacetate reveals promising sulfur removal (98.5\%) for $2 \mathrm{~h}$ compared with CdOx NPs (97.7\%) for $3 \mathrm{~h}$ in the presence of $\mathrm{H}_{2} \mathrm{O}_{2}$ and acetic acid as oxidizing agents and acetonitrile as a solvent. Under sunlight, sulfur content decreased from $11500 \mathrm{ppm}$ to $65 \mathrm{ppm}$ (removal exceeds $99.4 \%$ for the Cd diacetate against $98.0 \%$ for CdOx NPs) with high-quality properties (aniline point: $91.8{ }^{\circ} \mathrm{C}$, diesel index: 79.8). The photo-luminance activity of Cd diacetate (low intensity) allows reducing electron/hole pair recombination, which maintains stable photocatalytic activity with enhanced visible light elimi-nation of organosulfur compounds for economical, clean fuel production associated with pollution control. The catalyst recycling and the spontaneous regeneration of the solvent make the process very attractive. Cd diacetate was successfully recycled over six cycles.
\end{abstract}

\section{Introduction}

The combustion of a fuel produces intense emissions of sulfur dioxide that, in turn, strongly impacts the environment through air pollution and acid rains (Dharaskar et al., 2014). For these reasons, international institutions have driven incentive politics for regulating the content of sulfur compounds in fuels for transportation and industrial uses, targeting to produce and use ultra-low sulfur diesel (ULSD) (de Leon et al., 2019). The limit levels for S content in the fuels depend on their use in cars, buses, ships, and industry: 10

\footnotetext{
* Corresponding author.

** Corresponding author.

E-mail addresses: asma_2000asma@yahoo.com (A.S. Morshedy) sahartawfikepri@yahoo.com (S.M. Tawfik), kimoshouman1@gmail.com (K.M. Hashem), dina3032012@gmail.com (D.M. Abd El-Aty), galhoum_nma@ yahoo.com (A.A. Galhoum), eldeepmohsen@yahoo.com (M.S. Mostafa), Eric. Guibal@mines-ales.fr (E. Guibal)
}

or $15 \mathrm{ppm}$ for automotive engines and up to $500 \mathrm{ppm}$ for truck and shipping uses (de Leon et al., 2019; Zhang, L. et al., 2017a).

Hydrodesulfurization (HDS) was, for the last decades, the most usual process for "sulfur cleaning" of fuels. However, HDS usually requires severe operating conditions (such as elevated temperatures and pressures); also, the process frequently fails to eliminate branched refractory aromatic sulfur compounds. These different drawbacks make HDS poorly competitive (Javadli and de Klerk, 2012). Thus, many alternative desulfurization methods have been recently developed, such as adsorptive desulfurization (Hong et al., 2018; Jha et al., 2019; Ullah et al., 2019) and biodesulfurization (Chen et al., 2018; Etemadi et al., 2018). Extractive desulfurization (EDS) has also retained great attention for the last decade (Gao et al., 2018; Gutierrez et al., 2018). EDS was carried out using organic solvents as extracting agents such as DMSO and DMF (Zhao et al., 2015); however, their volatility and flammability represent critical drawbacks that were overcome using ionic liquids (Abro et al., 2014; Dharaskar et al., 2013; Gao et al., 2015; Ren et al., 
2018). Oxidative desulfurization has also retained great attention using a wide range of metal-based compounds like phosphotungstate (Zeng et al., 2019), cerium and molybdenum (Miao et al., 2016) immobilized on different porous supports such as polymer (Jiang et al., 2018), mineral phase (Jatav and Srivastava, 2019; Juliao et al., 2019), chemically-modified silica(Hu et al., 2018), graphene oxide (Dizaji et al., 2019) or in a liquid phase like ionic liquid/metal ion systems (Zhang, L. et al., 2017b). In the oxidative desulfurization process, the organic sulfur compounds are oxidized to their corresponding sulfones, which can be easily removed by a subsequent step such as extraction (Hassan et al., 2013), adsorption or decomposition methods (Ko et al., 2007; Landau et al., 2008). Different oxidizing agents such as $\mathrm{H}_{2} \mathrm{O}_{2}$, ozone, t-butyl hydroperoxide, t-butyl hypochlorite $(\mathrm{t}-\mathrm{BuOCl})$ have been used in various studies focused on oxidative desulfurization. $\mathrm{H}_{2} \mathrm{O}_{2}$ is a rather slow oxidizing agent, but it becomes extremely active in the presence of a catalyst (Al-Shahrani et al., 2007; García-Gutiérrez et al., 2008).

Photocatalysis route is used for activating the oxidative desulfurization of sulfur compounds from fuels (Amjed et al., 2017; Barmala et al., 2018; Liu et al., 2018; Miao et al., 2015; Wang, X. et al., 2014a; Zeng et al., 2017). Several heavy metals also present interesting optical properties, such as cadmium (Seo, 2004). The photo-catalysts that are based on Cd can be used both as solid materials and associated with ionic liquids.

Cadmium oxide, $\mathrm{CdO}$, recognized as an n-type semiconductor, is characterized by direct band-gap energy of $2.2-2.5 \mathrm{eV}$ and an indirect band-gap of 1.36-1.98 eV (Dong and Zhu, 2003; GradoCaffaro and Grado-Caffaro, 2008; Kalathur, 2005; Vinodkumar et al., 2010).

This work describes the synthesis of novel liquid cadmium based diacetate photo-catalyst for photo-desulfurization of sulfurcontaining diesel, by the reaction of cadmium with acetate ions, "controlled" under photo-irradiation, and constant flipping at room temperature. The UV or sunlight irradiation ionizes the metal in water to form hydroxide species before reacting with acetic acid to form soluble hydrated cadmium diacetate species. The lightinduced energy induces the reactive melting of acetate and cadmium, with the formation of coordinating chemical bonds between acetate and a combination of water molecules and the release of halogen ions. Under non-controlled conditions (i.e., without irradiation), the residual products would be poorly soluble in water.

The photocatalytic performance is compared with the more conventional solid CdO NPs in the desulfurization treatment of diesel fuel (Morshedy et al., 2016). The effect of different parameters such as irradiation type, catalyst dosage, oxidizing agents, and solvent extraction on sulfur removal was investigated. The results showed that the liquid cadmium diacetate photo-catalyst could operate under visible light irradiation and sunlight, has higher desulfurization activity than that of the CdOx nanoparticles, can be recycled and reused many times to avoid secondary pollution. Cd diacetate photo-catalyst is considered a bridge between homogenous and heterogeneous catalysts. It combines the benefits of the two types, where it has proper mixing and high catalytic efficiency as a homogenous catalyst and quickly separation after process with high reusability without a decrease in its activity like a heterogeneous catalyst. So, this is a potential catalyst for effective desulfurization to produce clean diesel.

\section{Materials and methods}

\subsection{Materials}

$\mathrm{Cd}\left(\mathrm{NO}_{3}\right)_{2} * 4 \mathrm{H}_{2} \mathrm{O}$ was purchased from LOBA Chemie (Mumbai, India). Acetic acid $(99.8 \%, \mathrm{w} / \mathrm{w})$, dibenzothiophene (DBT, 98\%), hydrogen peroxide $(30 \%, \mathrm{w} / \mathrm{w})$, acetonitrile $(99.8 \%)$, and $\mathrm{CCl}_{4}$ were supplied by Sigma-Aldrich (Dorset, UK). Ammonium hydroxide solution (37\%, w/w) and anhydrous calcium chloride were purchased from Merck (Darmstadt, Germany), and toluene (99\%) was obtained from Fischer (USA). The chemicals were used as received without treatment. Linear halogen lamp 500 Watt (550 nm), Xenon lamp 500 Watt $(500 \mathrm{~nm})$, ultraviolet lamp (UVC) $300 \mathrm{~W}(254 \mathrm{~nm})$ and ultraviolet lamp (UVA) $300 \mathrm{~W}$ (385 nm) were purchased from Abo-Sembol Company (Cairo, Egypt - as a representative of LightSources, Orange, CT (USA), https://www.light-sources.com).

\subsection{Synthesis of photo-catalysts}

\subsubsection{Synthesis of mixed cadmium oxides nanoparticles (CdOxNPs)}

Cadmium oxide nanoparticles were prepared at room temperature by the ammonia gas diffusion method. One hundred $\mathrm{mL}$ of $0.1 \mathrm{M} \mathrm{Cd}\left(\mathrm{NO}_{3}\right)_{2} * 4 \mathrm{H}_{2} \mathrm{O}$ aqueous solution was prepared by dissolving the salt in deionized water and heated up to $70{ }^{\circ} \mathrm{C}$. Ammonia gas was directly injected and diffused into the mixture by a Teflon pipeline ( $5 \mathrm{~mm}$ internal diameter) from an ammonia bottle (stored at $20^{\circ} \mathrm{C}$ ). The solution became cloudy, and then turned to a white color; a bright white precipitate of Cd-hydroxide particles was formed. After settling, the supernatant was decanted and filtered on a Buchner funnel. The precipitate was repeatedly washed with deionized water and dried at $120{ }^{\circ} \mathrm{C}$ overnight. The sample was then removed and lightly crushed in a mortar and pestle. The oxide catalyst CdOx nanoparticles were obtained by calcination at $500{ }^{\circ} \mathrm{C}$ for $6 \mathrm{~h}$ under air atmosphere. The current method is an alternative to the precipitation method discussed in a previous work that consisted of using $\mathrm{NaOH}$ as the precipitating agent (Morshedy et al., 2016). Although the synthesis procedures are entirely different, the experimental conditions have been adjusted to maintain the same amount of cadmium during the photocatalytic experiments for both CdOx NPs and Cd diacetate, by the control of starting initial molar ratio.

\subsubsection{Synthesis of active Cd-diacetate (photo liquid)}

The method for the preparation of photo-active soluble $\mathrm{Cd}$ diacetate is schematized in Equations (1) and (2). A fixed amount of $\mathrm{Cd}\left(\mathrm{NO}_{3}\right)_{2} * 4 \mathrm{H}_{2} \mathrm{O}(0.1 \mathrm{~mol})$ was dissolved into $100 \mathrm{~mL}$ of deionized water in a $500 \mathrm{~mL}$-volume glass beaker before adding $0.2 \mathrm{~mol}$ of acetic acid under continuous stirring. The reaction took place under ultraviolet irradiation (using a $300 \mathrm{~W} / 254 \mathrm{~nm}$ lamp) for 30-40 min. The light exposure and agitation were stopped, and the solution was left for settling for 30-40 min until obtaining a transparent liquid. The resulting active photo liquid was stored in a dark glass flask until photocatalytic tests.

$$
\begin{aligned}
& \mathrm{Cd}\left(\mathrm{NO}_{3}\right)_{2} \cdot 4 \mathrm{H}_{2} \mathrm{O}+2 \mathrm{H}_{2} \mathrm{O} \stackrel{\mathrm{hu}}{\rightarrow} \mathrm{Cd}^{2+}+2 \mathrm{NO}_{3}^{-}+3 \mathrm{H}_{3} \mathrm{O}^{+} \\
& \quad+3 \mathrm{OH}^{-} \rightarrow \mathrm{Cd}(\mathrm{OH})_{2}+2 \mathrm{HNO}_{3}+\mathrm{H}_{2} \mathrm{O} \\
& \mathrm{Cd}(\mathrm{OH})(\mathrm{OH})_{2}+\mathrm{nH}_{2} \mathrm{O} \\
& \quad+2 \mathrm{CH}_{3} \mathrm{COOH} \stackrel{\mathrm{h} u}{\rightarrow} n\left(\mathrm{H}_{2} \mathrm{O}\right) \cdot \cdot \mathrm{Cd}\left(\mathrm{OOCH}_{3}\right)_{2}
\end{aligned}
$$

\subsection{Characterization of the photo-catalysts}

The synthesized materials were characterized using different analytical tools (depending on the physical state of the photocatalyst: either liquid or solid-state). Powder X-ray diffraction (XRD) experiments were conducted at room temperature for the fresh catalyst using a Bruker AXS-D8 Advance XRD spectrometer (Karlsruhe, Germany). The patterns were recorded using $\mathrm{Cu} \mathrm{K}_{\alpha}$ 
radiation $(\mathrm{k}=0.15405 \mathrm{~nm})$ and scanning the $2 \theta$ angle from 10 to $70^{\circ}$ (scanning speed: $0.4^{\circ} / \mathrm{min}$ ). Differential scanning calorimetry (DSC) and thermogravimetric analysis (TGA) characterizations were obtained using an SDT-Q600 V20.5 Pouild 15 (TA Instruments, New Castle, DE, USA). Textural properties (surface area and pore volume) were determined from nitrogen adsorption-desorption isotherms deduced from linear BET plots using Quantachrome Nova 3200 instrument (Boynton Beach, FL, USA). The accuracy in simulated isotherm curves exceeded 99.7\%. The samples were degassed at $120^{\circ} \mathrm{C}$ for $2 \mathrm{~h}$ under vacuum before analysis. Degassing conditions were selected based on DSC-TGA results to remove interstitial water without affecting the inter-layer water and preserving the gel-like structure of parental $\mathrm{Cd}(\mathrm{OH})_{2}$. The scanning electron microscope for the prepared samples using SEM model Quanta 250 FEG (Field Emission Gun), FEI, Thermo Fisher Scientific, Hillsboro, OR, USA attached to EDX unit (Energy Dispersive X-ray Analyses), with accelerating voltage $30 \mathrm{~K} . \mathrm{V}$., magnification $14 \mathrm{X}$ up to 100000 . The morphological, as well as microstructural features of the prepared oxide, were monitored using a high-resolution transmission electron microscope (HRTEM, Model JEM-2100 F, JEOL, Tokyo, Japan). A small amount of sample was dispersed in $10 \mathrm{~mL}$ ethanol and then sonicated for $15 \mathrm{~min}$. A few drops from the suspension were placed on a covered copper grid before being analyzed. Raman spectroscopy was performed at room temperature using SENTERRA Dispersive Raman Microscope (Bruker, Billerica, MA, USA) equipped with an Nd diode, a YAG laser operating at a wavelength of $532 \mathrm{~nm}$, with spectrum range between 500 and $2000 \mathrm{~cm}^{-1} .{ }^{13} \mathrm{C}$ NMR spectra were recorded using DMSO as the solvent on a Bruker High-Performance Digital FT-NMR spectrometer Avance III $400 \mathrm{MHz}$ (Bruker, Billerica, MA, USA). Elemental analysis was performed with a Vario EL III Germany element microanalyzer (Elementar Analysensysteme $\mathrm{GmbH}$, Langensenbold, Germany). Cadmium content was directly determined in Cd diacetate solutions by atomic absorption spectrometry (Savant AA spectrometer, GBC Scientific Equipment, Braeside, Australia). The sulfur content in the samples before and after treatment was determined using a Spectro Phoenix II X-ray fluorescence analyzer (Ametek Process Instruments, Pittsburgh, PA, USA). The tolerance of the X-ray fluorescence device was $\pm 3 \mathrm{ppm}$. The experiments were systematically triplicated (both for desulfurization properties and for material characterization). The photoluminescence characteristics were determined at room temperature using a spectrofluorometer (JASCO FP-6500, Jasco International CO., Ltd., Tokyo, Japan) with an excitation wavelength set at $\lambda=300 \mathrm{~nm}$. X-ray photoelectron spectroscopy (XPS) was collected on the K-Alpha spectrometer (Thermo Fisher Scientific, Waltham, MA, USA) with monochromatic X-ray $\mathrm{Al} \mathrm{K}_{\alpha}$ radiation (binding energy, $\mathrm{BE}$, up to $1350 \mathrm{eV}$ ). The spot size was $400 \mu \mathrm{m}$. Measurements were performed under a pressure of $10^{-9} \mathrm{mbar}$. For the survey spectrum, the energy step was $200 \mathrm{eV}$ and $50 \mathrm{eV}$ for high-resolution spectra (HRES).

\subsection{Activity measurements}

Desulfurization experiments were carried out in a doublejacketed photo-reactor running on batch mode. The total capacity of the reactor was $200 \mathrm{~mL}$. A water-cooling system controlled the temperature during the photo-reaction. The desulfurization processes started by loading both the photo-catalyst (either the photo liquid Cd-diacetate or CdOx NPs) and the feedstock into the reactor. It is noteworthy that the two solutions (meaning feedstock and photo liquid Cd diacetate) are immiscible. Batch experiments were simply carried out by equilibrating equal volumes of the two solutions in stoppered glass bottles using a magnetic stirrer; the concentration of the photo-catalyst was $8.8 \times 10^{-3} \mathrm{M}$. The whole system was then exposed to the irradiation source to initiate the process (Morshedy et al., 2016). Blank experiments without photocatalysts and irradiation were systematically carried out: for example, the specific absorption of sulfur in $\mathrm{Cd}$ diacetate did not exceed $12 \%$ while for CdOx, the sorption did not exceed 3.5\% in the dark. Four different irradiation modes were tested: (a) a linear halogen lamp and a Xenon lamp for visible light (power: $500 \mathrm{~W}$ ), and (b) two ultraviolet sources (power: $300 \mathrm{~W}$ ). Both the feedstock and oxidized products (collected after substrate desulfurization) were treated by solvent extraction (in a jacketed mixer-settler batch apparatus) under vigorous agitation for $45 \mathrm{~min}$. The extraction temperature was adjusted to $50 \pm 1{ }^{\circ} \mathrm{C}$ (using an ultrathermostat). After settling for $45 \mathrm{~min}$, the two phases (feed or sample and solvent) were separated. The solvent was removed from the raffinate phase by washing several times with hot distilled water. The raffinate was then dried over anhydrous calcium chloride. The solvent was eliminated from the extract phase by distillation under reduced pressure (Morshedy et al., 2016). The yield of desulfurization was calculated by comparison of initial and final sulfur compounds on the diesel phases. It is noteworthy that the two solutions (feedstock and photo liquid $\mathrm{Cd}$ diacetate) are immiscible.

The heterogeneous photo-catalyst ( $\mathrm{Cd}$ diacetate) was regenerated after each catalytic step before being reused. After each oxidative desulfurization (ODS) run, the photo-liquid phase was distilled in an oil bath at $110{ }^{\circ} \mathrm{C}$ to remove impurities (residual $\mathrm{H}_{2} \mathrm{O}_{2}$ and water). Then, the photo-liquids were further dried at $100{ }^{\circ} \mathrm{C}$ under vacuum to remove the trace amounts of water; then, it was regenerated by re-extraction in carbon tetrachloride to remove the traces of oxidation products of sulfur compounds in the photoliquid phase. The spent catalyst after being reused six times was forwarded to the recovery stage. The spent catalyst was washed using benzene, followed by rinsing with ethanol and distilled water. The cleaned catalyst was dried and then re-analyzed by FTIR: the FTIR fingerprint of treated catalyst revealed identical to the profile of the freshly prepared catalyst. The material is efficiently and readily regenerated; this makes the overall process easy and competitive.

The efficiency in the desulfurization and regeneration can be improved using a solvent extraction step after oxidation operation. Another test was performed using acetonitrile for evaluating the beneficial effect of this complementary step. The solvent/feed ratio $(\mathrm{S} / \mathrm{F})$ was varied between $1: 1$ and $4: 1$. The extraction process was carried out in a double-jacketed reactor under mechanical stirring (at $500 \mathrm{rpm}$ ) at the temperature of $50^{\circ} \mathrm{C}$. The reaction time was set at $45 \mathrm{~min}$; after a settling time of $45 \mathrm{~min}$, the phases were separated: the diesel fraction was washed with hot distilled water and dried with $\mathrm{CaCl}_{2}$ for $24 \mathrm{~h}$. The characteristics of the diesel samples were recorded (i.e., recovery yield, sulfur content, refractive index, density, aniline point, and diesel index).

\subsection{Characterization of diesel fuel}

The feed and the treated diesel fuel were characterized using the standard methods established by ASTM (American Society for Testing and Materials). Table AM1 (see Additional Material Section, AMS) summarizes these methods.

The analysis of DBT organic phase was performed by gas chromatography (GC) using an Agilent 7890 A GC equipped with a flame ionization detector (FID) and a capillary column (Agilent 19091Z$530,100 \mathrm{~m} \times 250 \mu \mathrm{m} \times 0.5 \mu \mathrm{m}$ ). Analyses were performed using $\mathrm{N}_{2}$ as the carrier gas; the injector and detector temperatures were set to $100{ }^{\circ} \mathrm{C}$ and $310^{\circ} \mathrm{C}$, respectively. The temperature of the column was varied between $200{ }^{\circ} \mathrm{C}$ and $250{ }^{\circ} \mathrm{C}$ for $45 \mathrm{~min}$ (temperature ramp: $10^{\circ} \mathrm{C} / \mathrm{min}$ ). Perkin Elmer gas chromatograph occupied with a 
flame photometric detector (GC-FPD) was used for the analysis of both products and reactive species of sulfur compounds in diesel fuel during the process. A capillary column MXT- 1 packed with thin-film $0.25 \mathrm{~mm}$ of polymethylpolysiloxane, the column length $30 \mathrm{~m}$, and internal diameter $0.25 \mathrm{~mm}$. The initial temperature is $70{ }^{\circ} \mathrm{C}$ and the final temperature is $300^{\circ} \mathrm{C}$ with a heating rate of $5^{\circ} /$ min. The injector and detector temperatures were $300{ }^{\circ} \mathrm{C}$ for both. The used mobile phase (carrier gas) is helium with a flow rate of $2 \mathrm{ml} \mathrm{min}{ }^{-1}$. The identification of the sulfur compounds was achieved by using some standard sulfur compounds (as thiophene, benzothiophene and dibenzothiophene) besides the help of the previous literature using the same column and same detector.

\section{Results and discussion}

\subsection{Characterization of photo-catalysts}

\subsubsection{Thermal analysis}

The synthesis procedure for $\mathrm{CdOx}$ nanoparticles consists of two steps: (a) the formation of $\mathrm{Cd}(\mathrm{OH})_{2}$, followed by (b) the calcination of the metal hydroxide at $500{ }^{\circ} \mathrm{C}$. The TGA and DTG analyses of $\mathrm{Cd}(\mathrm{OH})_{2}$ shows a marginal loss of water (less than $0.3 \%$ of total weight) till a temperature of $110{ }^{\circ} \mathrm{C}$ (Figure AM1a, see Additional Material Section, AMS): this is expected since the metal hydroxide was dried at $120^{\circ} \mathrm{C}$ during the synthesis, the uptake of water before TGA measurements was negligible. Above $120^{\circ} \mathrm{C}$ and up to $380^{\circ} \mathrm{C}$, the weight decreases by $13.4 \%$ (total loss: $13.7 \%$ ). This step in the process corresponds to a steep DTA peak at $232{ }^{\circ} \mathrm{C}$. This step is usually associated with the loss of water in the crystal lattice due to the conversion of $\mathrm{Cd}(\mathrm{OH})_{2}$ into $\mathrm{CdOx}$. Thomas and Abraham observed similar trends for the TG analysis of $\mathrm{Cd}(\mathrm{OH})_{2}$ as a precursor of CdO (Thomas and Abraham, 2015). Based on the respective chemical formula, the weight loss should be close to $13.5 \%$; this is consistent with the measured loss of weight. Between $380^{\circ} \mathrm{C}$ and $1000^{\circ} \mathrm{C}$, the mass of the product remains constant, while the DTG linearly decreases and reaches a minimum at around $928^{\circ} \mathrm{C}$. Above $1000{ }^{\circ} \mathrm{C}$, the weight decreases due to the volatilization of $\mathrm{CdOx}$ (Manjunatha et al., 2012). The same thermal analysis was performed on CdOx NPs (Figure AM1b, see AMS). A first weak weight loss (about $0.3 \%$ ) occurs below $150{ }^{\circ} \mathrm{C}$ due to water release; below $1000{ }^{\circ} \mathrm{C}$, the total weight loss does not exceed $1.8 \%$. Above $1000^{\circ} \mathrm{C}$, the vaporization of CdOx NPs occurs. In the thermal degradation of CdOx NPs prepared by the sol-gel method, Vadgama et al. reported two phases (Vadgama et al., 2017): (a) first, the removal of adsorbed water, followed by (b) a progressive loss of weight up to $950{ }^{\circ} \mathrm{C}$ (which represents up to $10 \%$ ).

On the DTA profiles, the peaks (or poorly resolved shoulders) below $200^{\circ} \mathrm{C}$, which are associated with the loss of adsorbed water, are endothermic. Above $200{ }^{\circ} \mathrm{C}$, exothermic peaks appear; they correspond to the phase transition between the metal hydroxide and the oxide phase.

\subsubsection{XRD analysis}

The XRD pattern of CdOx NPs is shown in Figure AM2 (See AMS); the material was produced by annealing $\mathrm{Cd}(\mathrm{OH})_{2}$ at $500{ }^{\circ} \mathrm{C}$ for $6 \mathrm{~h}$. The pattern shows five main reflections centered around $2 \theta=33.04^{\circ}, 38.33^{\circ}, 55.33^{\circ}, 65.98^{\circ}$, and $69.31^{\circ}$ corresponding to (111), (200), (220), (312) and (222) planes, with a lattice constant $\mathrm{a}_{\mathrm{o}}=4.6920 \AA$ A This structure is identified as mixed-phase of the cubic phase of CdOx (JCPDS 00-001-1049) (Magdalane et al., 2016; Reddy et al., 2018; Tadjarodi and Imani, 2011b) and $\mathrm{CdO}_{2}(00-039-$ 1221), the two phases were also confirmed through XPS analysis (section 3.1.8.).The absence of any additional peaks confirms the high purity CdOx NPs. It is noteworthy that the five planes appear under the form of split peaks. This may be attributed to the formation of two phases. This is consistent with the TEM observation that shows two phases or morphology of crystals (see section 3.1.4.). In the case of pyridine-capped CdOx crystals (which have some hexagonal nanostructures), the planes were also identified at very close values of $2 \theta$ (Anandhan et al., 2019).

\subsubsection{Textural characteristics of CdOx NPs - BET analysis}

Figure AM3 (See AMS) shows $\mathrm{N}_{2}$ sorption/desorption isotherms and $\mathrm{BJH}$ analysis of textural properties. A (weak) hysteresis gap is observed between sorption and desorption isotherms; this is typical of Type IV isotherm, as defined by Brunauer (though the general shape of the profiles approaches the Type II isotherm). The material has a low specific surface (i.e., $S_{\text {BET }}=11.2 \mathrm{~m}^{2} \mathrm{~g}^{-1}$ ). The order of magnitude of the specific surface area means that this surface area is essentially due to the external surface of micro-/ nano-particles. The small total pore volume of the metal oxide confirms the poor intrinsic porosity: $V_{p}=0.02235 \mathrm{~cm}^{3} \mathrm{~g}^{-1}$. Figure AM3b shows a tri-modal distribution of pores corresponding to $2.5 \mathrm{~nm}, 3.4 \mathrm{~nm}$, and $5.6 \mathrm{~nm}$ (with a long tailing). These textural properties are "lower" than those reported by Reddy et al. (i.e., $\mathrm{S}_{\mathrm{BET}}=50.8 \mathrm{~m}^{2} \mathrm{~g}^{-1} ; \mathrm{Vp}=0.032 \mathrm{~cm}^{3} \mathrm{~g}^{-1} ; \mathrm{r}_{\mathrm{p}}=38.2 \mathrm{~nm}$ ) (Reddy et al., 2018). The as-prepared CdOx photo-catalyst is micro-porous.

\subsubsection{Morphological characteristics of CdOx NPS - SEM and TEM analysis}

The SEM images (Figure AM4, See AMS) shows CdOx NPs have a wide distribution in size and shape; the particles are irregular and granular; they aggregate to form larger objects (size up to $50 \mu \mathrm{m}$ ): size distribution ranges between a few $\mu \mathrm{m}$ to $50 \mu \mathrm{m}$ at the macroscopic scale. The TEM images on dispersed nanoparticles show specific dispersion in size and the shape of nanocrystals (Figure AM5; See AMS): most of the nano-objects show facecentered cubic crystalline structures, with size below $20 \mathrm{~nm}$ (Reddy et al., 2018; Thomas and Abraham, 2015). The relevant XRD signals correspond to the f.c.c. CdOx crystals (XRD card). Hexagonal objects are also identified; they may be correlated to the splits observed on the XRD pattern (Figure AM2). Anandhan et al. reported similar hexagonal sheets when CdOx nanostructures were prepared in the presence of pyridine as the capping agent (Anandhan et al., 2019). In some cases, some aggregates are formed, probably due to the melting of adjacent crystals during the calcination step.

\subsubsection{Optical absorption - diffuse reflectance spectroscopy}

The UV-visible diffuse reflectance spectra of the two photocatalysts are reported in Fig. 1. They show very similar shapes, with a translation to higher reflectance for CdOx NPs compared with $\mathrm{Cd}$ diacetate. Two small peaks are observed in the visible wavelength range (at $296 \mathrm{~nm}$ and $338 \mathrm{~nm}$ ). However, the most significant variation appears in the range $460-540 \mathrm{~nm}$ with a sharp increase in the reflectance for the two photo-catalysts; a weak shoulder is also observed at $520 \mathrm{~nm}$. It is noteworthy that this edge is at a significantly higher wavelength than for other CdOx catalysts: Reddy et al. reported a sharp variation of absorbance at 370-380 nm (Reddy et al., 2018). A little (blue) shift toward lower wavelengths is detected for $\mathrm{Cd}$ diacetate compared with CdOx NPs. The direct band-gap (DBG) is calculated from Fig. 2: $(F(R) h u)^{2}$ is plotted $v s$. hu according to the Kubelka-Munk function equation, and the X-axis intercept of the tangent gives the DBG. For CdOx, the DBG is close to $2.50 \mathrm{eV}$ while for Cd diacetate, the value is a little lower (i.e., $2.42 \mathrm{eV}$ ). These values are lower than the DBG of comparable materials reported in the literature with CdO-based photocatalysts: above $3 \mathrm{eV}$ for CdO-doped $\mathrm{ZnO}$ films (Vinodkumar et al., 2010), $2.52 \mathrm{eV}$ for CdO nanocrystals (Ghoshal et al., 2009), 2.61 for CdO (Reddy et al., 2018). The nano-morphotype of CdO catalysts 


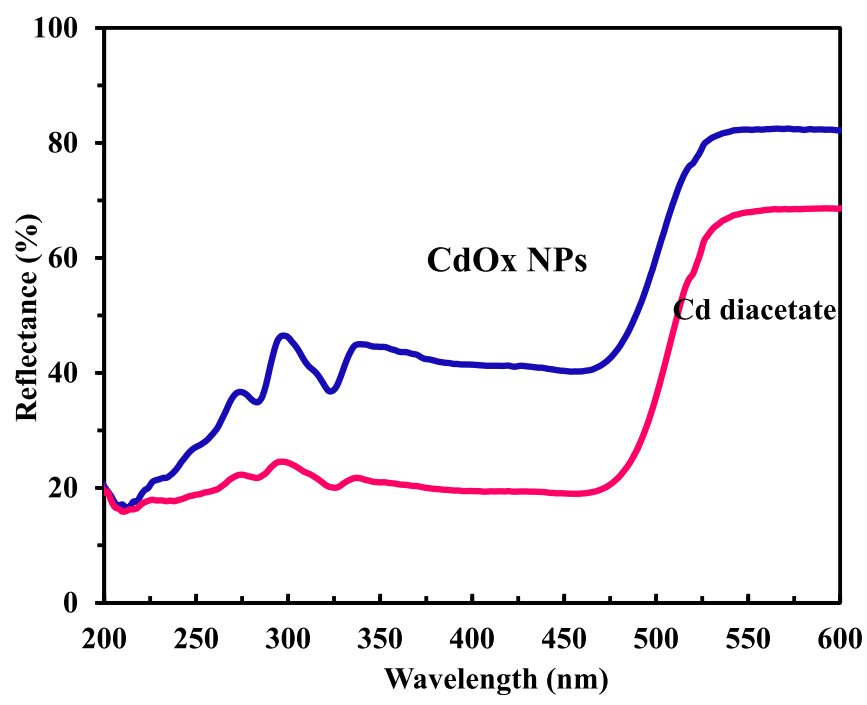

Fig. 1. Diffuse reflectance spectroscopy - UV-visible absorption spectra of CdOx NPs and $\mathrm{Cd}$ diacetate.

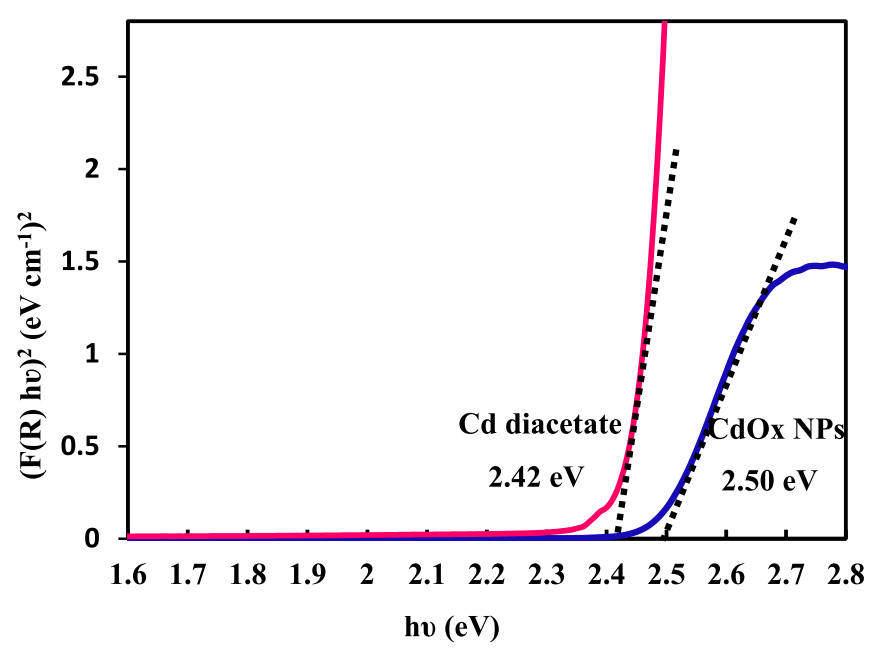

Fig. 2. Optical band gap energies for CdOx NPs and Cd diacetate photocatalysts.

influence their direct gap energy (Thomas and Abraham, 2015). The DBC is the reciprocal of the absorption band of the photo-catalyst and helps in determining the optimum light source for productive photocatalytic activity (in addition to other parameters intrinsically set by the substrate).

\subsubsection{Catalyst photoluminescence (PL)}

The ability of the material to promote photo-activated chemical reactions can also be documented by analyzing the photoluminescence of the sample. Figure AM6 (See AMS) shows the PL at room temperature of CdOx NPs, with an excitation wavelength: $\lambda=300 \mathrm{~nm}$. The major peak of luminescence appears at $\lambda: 469 \mathrm{~nm}$, with additional weak bands (shoulders) at $\lambda: 420 \mathrm{~nm}, 439 \mathrm{~nm}$, $452 \mathrm{~nm}, 482 \mathrm{~nm}$, and $492 \mathrm{~nm}$. This is in the blue region of the light spectrum, consistently with the observations of optical absorption (Section 3.1.5.). Under an emission wavelength of $353 \mathrm{~nm}$, Reddy et al. found a significant peak at $486 \mathrm{~nm}$ (Reddy et al., 2018), this peak is broad due to the convolution of different signals corresponding to different transitions. Cuba et al. deconvoluted the PL bands to identify different transitions and wavelengths (i.e., $430 \mathrm{~nm}, 455 \mathrm{~nm}$, and $483 \mathrm{~nm}$ ) for CdOx before and after annealing treatment at different temperatures (Cuba et al., 2018). Ashoka et al. reported a significant band at $483 \mathrm{~nm}$ under an excitation wavelength of $450 \mathrm{~nm}$ (Ashoka et al., 2010). Thomas and Abraham showed that the wavelength of the major photoluminescent peak decreases with excitation wavelength (in the range 350-450 nm) and is strongly controlled by the morphology of CdO crystals (Thomas and Abraham, 2015). Besides, the photoluminescence intensity decreases with the excitation wavelength.

The electrons in the valence band move first to the conduction band, before being stabilized by the photo-emission. The PL intensity increases with increasing the number of emitted electrons resulting from the rapid recombination between excited electrons and holes, which, in turn, reduces the photo-activity of the catalyst. The wavelength of emission is directly correlated to the energy band-gap due to the recombination of a photo-generated hole with an electron occupying the oxygen vacancy (Nezamzadeh-Ejhieh and Banan, 2011). The PL intensity of the CdOx catalyst was very low compared to the literature data. This means that the recombination of $\mathrm{h}^{+}$and $\mathrm{e}^{-}$at the surface of the catalyst is slower, and then the catalytic activity is enhanced (Morshedy et al., 2016). The direct comparison is made difficult by different excitation wavelengths; however, the difference in the order of magnitude is sufficient to demonstrate the activity of CdOx NPs. This probably means that the recombination of $\mathrm{h}^{+}$and $\mathrm{e}^{-}$is slow; this will undoubtedly affect the photocatalytic activity of CdOx NPs.

The low specific surface area of $\mathrm{CdOx}$ has a limited impact on CdOx NPs in the case of photocatalytic reaction; indeed, the critical parameter is the recombination of electrons between excited states and holes in the ground state. This is measured by the band-gap, which is undoubtedly more favorable for photo-liquid catalyst compared with CdOx NPs.

Figure AM6 (see AMS) also shows the PL spectrum for Cd diacetate. It is noteworthy that the peak shifts toward higher wavelengths (i.e., visible lights) with: (a) a broad maximum at around $550 \mathrm{~nm}$ and (b) an additional weak and broadband at $697 \mathrm{~nm}$. This wide range of wavelengths is especially essential for practical application since it fits even better to the visible spectra of sunlight. The lower PL intensity means again that the recombination of $\mathrm{h}^{+}-\mathrm{e}^{-}$is slow, meaning good photocatalytic activity.

\subsubsection{FTIR analysis}

Fig. 3 compares the FTIR spectra of CdOx NPs and Cd diacetate. Generally, the spectrum of CdOx NPs is less resolved than that of Cd diacetate; this is consistent with previous observations (Mazaheritehrani et al., 2010). The broadband centered around

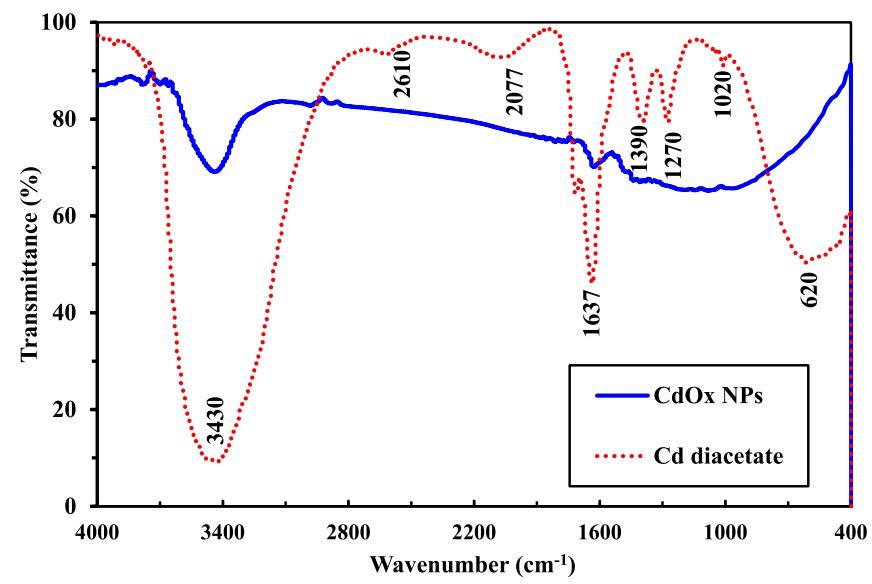

Fig. 3. IR spectra of as-prepared CdOx NPs and freshly synthesized Cd diacetate liquid. 
$3430 \mathrm{~cm}^{-1}$ is assigned to $-\mathrm{OH}$ stretching vibration, hydroxyl groups, and H-bonded vibrations. For CdOx NPs, a peak is observed at around $1630 \mathrm{~cm}^{-1}$. This could be attributed to traces of nitrogenbased compounds: since ammonia was used for synthesizing the precursor $\left(\mathrm{Cd}(\mathrm{OH})_{2}\right)$. A large unresolved band is observed between $1500 \mathrm{~cm}^{-1}$ and $700 \mathrm{~cm}^{-1}$ : a weak shoulder is detected around $1400 \mathrm{~cm}^{-1}$ (Mazaheritehrani et al., 2010). For Cd diacetate, the higher resolution facilitates the discussion. Significant peaks are observed at $1720 \mathrm{~cm}^{-1}$ (carboxylic acid, $\mathrm{C}=\mathrm{O}$ stretching), $1637 \mathrm{~cm}^{-1}$ ( $\mathrm{H}-\mathrm{O}-\mathrm{H}$ bending), $1390 \mathrm{~cm}^{-1}$ (carboxylate, $\mathrm{O}-\mathrm{H}$ bending) and $1270 \mathrm{~cm}^{-1}$ (C-O stretching) (Ito and Bernstein, 1956; Sutton et al., 2015). The small peak at $1020 \mathrm{~cm}^{-1}$ is assigned to $-\mathrm{CH}_{3}$ rocking vibration while the shoulder at $620 \mathrm{~cm}^{-1}$ is attributed to the wagging vibration of COO- involved in the interaction with a metal cation (Patil et al., 1968). The peak appearing at $822 \mathrm{~cm}^{-1}$ is assigned to $\mathrm{C}-\mathrm{H}$ bending vibration (Bedre et al., 2012). This series of bands and vibrations confirms the suggested formation of $\mathrm{Cd}$ diacetate.

\subsubsection{XPS analysis of mixed CdOx NPS}

$\mathrm{X}$-ray photoelectron spectroscopy was studied to determine the surface oxidation states and to understand the conversion of cadmium precursor to cadmium oxide species. Figure AM7a showed the spectrum of the complete survey of the prepared sample, which reverses the presence of different cadmium and oxygen species. As shown in Figure AM7 b, the 0 1s peak was deconvoluted into two peaks at binding energies 528.6 and 531.45 which corresponding to $\mathrm{CdOx}$ and $\mathrm{CdO}_{2} \& \mathrm{Cd}(\mathrm{OH})_{2}$ respectively (Majumder et al., 2019). The oxidation states of the $\mathrm{Cd}$ in the prepared sample were further analyzed using the XPS measurement. The Cd $3 \mathrm{~d}$ core-level spec-

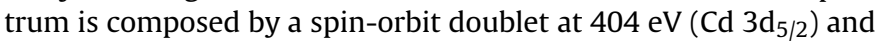

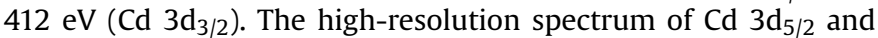
$3 \mathrm{~d}_{3 / 2}$ peaks reveals the presence of $\mathrm{Cd}$ in divalent- and tetravalent oxidation states. The peaks at 405.5 and $412.2 \mathrm{eV}$ (Majumder et al., 2019) are ascribed to the CdO, while those at 404.7 and $411.4 \mathrm{eV}$ are the characteristic peaks of $\mathrm{Cd}(\mathrm{OH})_{2}$. The tetravalent oxidation state of $\mathrm{Cd}$ is identified at 403.8 and $410.5 \mathrm{eV}$ (Achary et al., 2014). The obtained XPS data is in good agreement with the XRD pattern, which indicates the presence of mixed oxide phases of cadmium oxides. From the fitting of the spectrum, it results that the $C d 3 d_{5 / 2}$ component is located at $405.89 \mathrm{eV}$, and the spin-orbit splitting is of $6.74 \mathrm{eV}$. These results indicate that the NPs are composed by single CdO-related phase, as no traces from secondary phases such as $\mathrm{CdO}_{2}$ or $\mathrm{Cd}(\mathrm{OH})_{2}$ have been detected. Figure AM7c shows the deconvoluted peaks of $\mathrm{Cd} 3 \mathrm{~d}_{5 / 2}$ and $\mathrm{Cd} 3 \mathrm{~d}_{3 / 2}$. The observed peak of $\mathrm{Cd} 3 \mathrm{~d}_{5 / 2}$ was deconvoluted to three peaks located at $403.8 \mathrm{eV}$, $404.7 \mathrm{eV}$, and $405.5 \mathrm{eV}$ (Khallaf et al., 2011), which assigned to $\mathrm{CdO}_{2}, \mathrm{Cd}(\mathrm{OH})_{2}$ and $\mathrm{CdOx}$ species respectively. The three peaks deconvoluted from $\mathrm{Cd} 3 \mathrm{~d}_{3 / 2}$, which located at 410.5, 411.4, and $412.2 \mathrm{eV}$ (Majumder et al., 2019), maintain a fixed binding energy difference $(\sim 6.7 \mathrm{eV})$ from the corresponding $\mathrm{Cd} 3 \mathrm{~d}_{5 / 2}$ (Khallaf et al., 2011). The revealed data exported from XPS analysis was an agreement with the XRD pattern, which indicates the presence of mixed oxide phases of cadmium oxides.

\subsubsection{Raman analysis}

Fig. 4a shows the Raman spectra at room temperature of CdOx NPs; the spectrum shows poor information: $\mathrm{CdOx}$ is poorly active in Raman spectroscopy (Kaviyarasu et al., 2014; Popovic et al., 1991). Two broad peaks are detected at $270 \mathrm{~cm}^{-1}$ and $942 \mathrm{~cm}^{-1}$; they probably represent the convolution of different peaks. Albada et al. observed two peaks around $942 \mathrm{~cm}^{-1}$ in the case of di-copper bridging with hydroxyl groups (in scaffold amino acids bridged with copper) (Albada et al., 2007). Smaller peaks are detected at $550 \mathrm{~cm}^{-1}$ and $715 \mathrm{~cm}^{-1}$. Cuba et al. observed two peaks at $355 \mathrm{~cm}^{-1}$
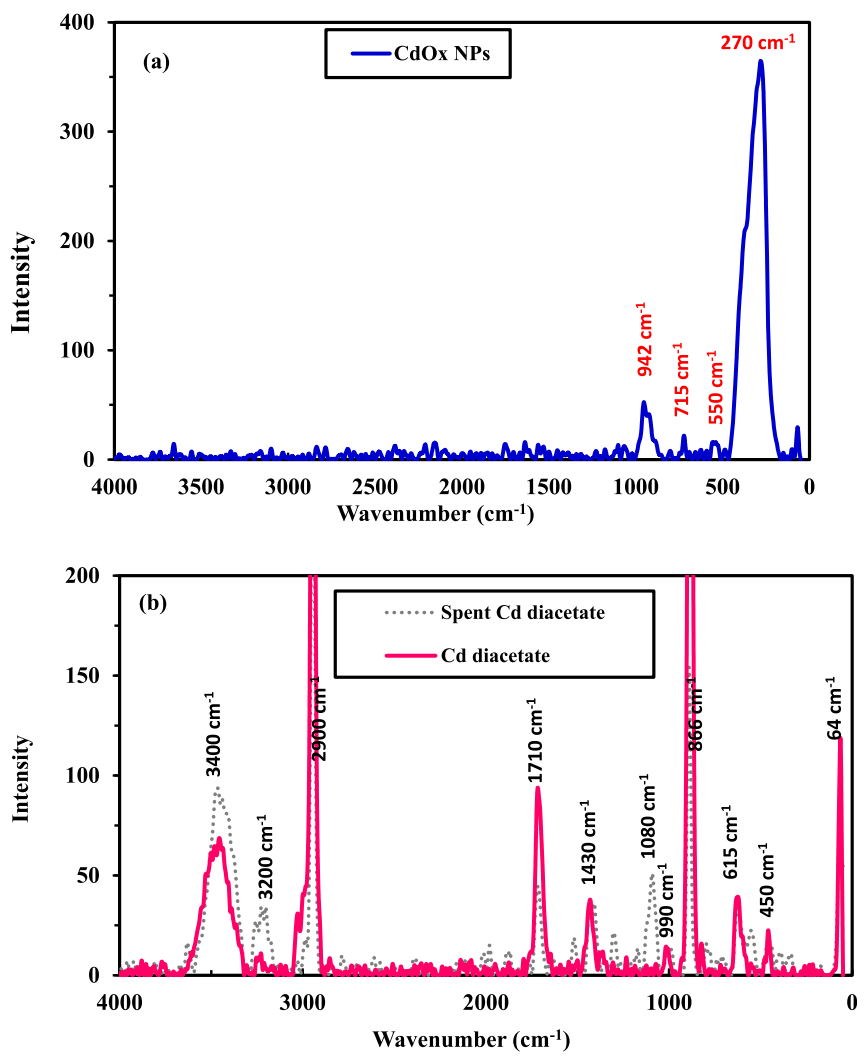

Fig. 4. Raman spectra of a) as-prepared CdOx NPs and b) freshly synthesized Cd diacetate photocatalysts and spent photocatalyst.

and $480 \mathrm{~cm}^{-1}$ that they precisely attributed to CdOx bands (Cuba et al., 2018); other detected peaks were assigned to impurities and residues produced during $\mathrm{CdOx}$ synthesis. Fig. 4b shows the Raman spectra for Cd diacetate freshly prepared and after being used. Numerous bands are observed (Krisnamurthy, 1962):

(a) broadband (3400-3200 $\mathrm{cm}^{-1}$ ), which is assigned to water molecules.

(b) broadband between $2900 \mathrm{~cm}^{-1}$ and $2800 \mathrm{~cm}^{-1}$, which is assigned to a series of $\mathrm{C}-\mathrm{H}$ stretching vibrations,

(c) eight sharp peaks at $1710 \mathrm{~cm}^{-1}(\mathrm{C}=\mathrm{O}), 1430 \mathrm{~cm}^{-1}\left(\mathrm{CH}_{3}\right.$ deformation), $1080 \mathrm{~cm}^{-1}$ (C-C stretching), $866 \mathrm{~cm}^{-1}$ (C-C stretching), $815 \mathrm{~cm}^{-1}$ (H-bending band) (Priebe et al., 2006), $615 \mathrm{~cm}^{-1}$ (COO deformation), $450 \mathrm{~cm}^{-1}$ (COO in-plane rocking) and $64 \mathrm{~cm}^{-1}$ (lattice signal) (Adar, 2016).

After being used, the Cd diacetate photo-catalyst shows roughly the same peaks; however, many new peaks appear, probably associated with the presence of products of oil/fuel desulfurization.

\subsubsection{NMR spectroscopic analysis of $C d$ diacetate}

Figure AM8 (see AMS) shows the ${ }^{13} \mathrm{C}$ NMR spectrum of $\mathrm{Cd}$ diacetate. Typical peaks of $\mathrm{CH}_{3}$ and $\mathrm{C}=\mathrm{O}$ groups are identified at $20.9 \mathrm{ppm}$ and $175 \mathrm{ppm}$, respectively. A small broad peak is detected close to $40 \mathrm{ppm}$ : this band corresponds to the convolution of 7 peaks in the range 37.85-39.11 ppm. Figure AM9 (see AMS) shows the ${ }^{1} \mathrm{H}$ NMR spectrum of the photo-catalyst: 2 peaks at $1.87 \mathrm{ppm}$ and $11.11 \mathrm{ppm}$ are observed; they are attributed to the two methyl groups (Singlet, $6 \mathrm{H}$ ) and the $-\mathrm{OH}$ group (broad singlet, $1 \mathrm{H}$ ), respectively (Hatada et al., 1981; Kamide and Okajima, 1981; Kowsaka et al., 1986). These $(-\mathrm{OH})$ groups mean that a water 
molecule is present in the structure of cadmium diacetate. Both ${ }^{13} \mathrm{C}$ and ${ }^{1} \mathrm{H}$ NMR confirm that hydrated cadmium diacetate is the main constituent of the photo-catalyst.

\subsubsection{Elemental analysis of $\mathrm{Cd}$ diacetate}

The expected formula of the photo-catalyst is represented by $\mathrm{Cd}\left(\mathrm{CH}_{3} \mathrm{COO}\right)_{2} * \mathrm{H}_{2} \mathrm{O}$ (i.e., $\left.\mathrm{CdC}_{4} \mathrm{H}_{8} \mathrm{O}_{5}\right)$. The $\mathrm{C}, \mathrm{H}, \mathrm{O}, \mathrm{N}$ analysis of the sample (where $\mathrm{N}$ is not detected, and $\mathrm{O}$ is obtained by difference to $100 \%$ weight fraction) gives the following weight percentages for C, H, O: $19.56 \%, 3.28 \%$, and $32.05 \%$, respectively. Cadmium content was analyzed by atomic absorption: the corresponding weight fraction is $45.11 \%$. These values are very close to theoretically calculated values: $19.33 \%, 3.24 \%, 32.19 \%$, respectively and $45.23 \%$ for Cd. Elemental analysis confirms the expected structure deduced from other analytical procedures.

\subsubsection{General comparison of the characteristics of the photo- catalysts with comparable materials}

Table AM2 (see AMS) reports some examples of CdOx-based photo-catalysts obtained with different methods (Ashoka et al, 2010; Dong and Zhu, 2003; Ghoshal et al., 2009; Gulino et al., 2003; Ranjbar and Morsali, 2011; Tadjarodi and Imani, 2011a, b; Varghese et al., 2007; Yakuphanoglu, 2010; Zhang and Wang, 2008; Ziabari and Ghodsi, 2011). The procedure used for synthesizing CdOx NPs (i.e., ammonia gas diffusion) produces nanoparticles among the smallest in the panel reported in the table; their crystallinity differs from the crystalline forms of other catalysts. The energy gaps (Eg) are of the same order of magnitude than for the other materials, and the emission peaks are among the highest wavelengths (i.e., closer to visible spectrum).

\subsection{Evaluation of photocatalytic activity on model oil and diesel} fuel

\subsubsection{Influence of the radiation source}

The first step in the study consisted of testing the activities of the two catalysts in the dark. This experiment is a kind of control test for carefully identifying the effect of irradiation (in the next steps). The reaction was performed in a double-jacketed reactor (volume: $200 \mathrm{~mL}$ ) connected to a cooling water system. After $24 \mathrm{~h}$ of reaction, the photo-catalyst was separated from diesel by phase separation (liquid photo-catalyst) or filtration (Cd NPs), and the residual amount of sulfur in the diesel phase was quantified by Xray fluorescence spectrometry (Morshedy et al., 2016). Figure AM10 (see AMS) compares the removal efficiencies for the two systems: low desulfurization activities are observed. However, even in the dark, liquid photo-catalyst is more efficient than Cd NPs. The equilibrium is reached within 30 min of contact; Cd NPs remove only $5.4 \%$ of sulfur while the yield reaches $12.2 \%$ for the Cd diacetate system. It is noteworthy that the systems have substantially different kinetic profiles. For Cd NPs, $65 \%$ of total removal occurs within 5 min and almost $93 \%$ after $15 \mathrm{~min}$, while for the Cd diacetate system, the yield does not exceed $41 \%$ and $61 \%$ of total removal, respectively. The $15-25$ min reaction time is more active for $\mathrm{Cd}$ diacetate. The pseudo-first-order rate equation can be used for approaching the kinetic reaction parameter. The slope of the linear section of the plot of $\ln \left(\mathrm{C}(\mathrm{t}) / \mathrm{C}_{0}\right)$ vs. time gives the apparent rate coefficient: $4.2 \times 10^{-3} \mathrm{~min}^{-1}$ and $2.6 \times 10^{-3} \mathrm{~min}^{-1}$ for $\mathrm{Cd}$ diacetate and CdOx NPs, respectively. Also, the characterization of the diesel after-treatment shows that: (a) the aniline point was almost unchanged (slightly increasing from $74^{\circ} \mathrm{C}$ to $75^{\circ} \mathrm{C}$ for $\mathrm{CdOx}$ NPs and $76{ }^{\circ} \mathrm{C}$ for (d diacetate), and (b) the diesel index remained close to 54.5 (55.2 for CdOx NPs and 56.0 for Cd diacetate).

In a second step, the same experimental procedure is used for investigating the effect of irradiation mode on diesel desulfurization. The reaction time was set to $3 \mathrm{~h}$. Four different types of lamps were tested: (a) two visible light lamps (xenon lamp and linear halogen lamp, LHL), and (b) two UV lamps (near visible irradiation, i.e., UVA lamp; and far UV lamp; i.e., UVC lamp). The radiation power was kept constant at $500 \mathrm{~W}$ for visible lamps and at $300 \mathrm{~W}$ for UV lamps. The experiments were performed with different powers; the volume of treated solutions was proportionally adjusted. Fig. 5 compares the desulfurization efficiencies for the two photocatalytic systems. It is remarkable that for UV irradiation ( $\lambda_{\text {irrad. }} \leq 400 \mathrm{~nm}$; UVA: $400-315 \mathrm{~nm}$ and UVC: $280-$ $100 \mathrm{~nm}$ ), the desulfurization yield was similar to the levels reached in the dark (i.e., $5.3-5.5 \%$ and $12.1-12.5 \%$ for CdNPs and Cd diacetate, respectively). This conclusion is consistent with the properties observed in diffuse reflectance studies: the reflectance sharply increases above $450 \mathrm{~nm}$. Barmala et al. reported similar trends for the photo-oxidation of dibenzothiophene (DBT) on carbon nanotubes/titania composites under visible irradiation light (Barmala et al., 2018).

Under visible light irradiation, the desulfurization efficiency slightly increases for CdOx NPs: up to $6.9 \%$ and $8.2 \%$ for Xenon lamps and LHL, respectively. The benefit of visible light exposure is much more significant for $\mathrm{Cd}$ diacetate photo-catalyst; the yields are more than doubled: $20.5 \%$ and $25.8 \%$ for Xenon lamps and LHL lamps, respectively. This result is consistent with diffuse reflectance observations: Cd diacetate profile is shifted toward the visible region with lower energy demand compared to Cd NPs. The preference for LHL lamp, compared to Xenon lamp, is directly associated with: (a) the diffuse reflectance characteristics of the photocatalytic systems (respective shifts of their DRS spectra), and (b) the irradiation range of the lamps (wavelength, 500-550 nm for LHL lamp and $420-500 \mathrm{~nm}$ for Xenon lamp). It is noteworthy that the photoluminescence spectra (Figure AM6, see AMS) shows broadband between $400 \mathrm{~nm}$ and $500 \mathrm{~nm}$.

The treatment hardly changes the aniline point and the diesel index from $74^{\circ} \mathrm{C}$ to $78.8^{\circ} \mathrm{C}$ with Cd diacetate under LHL irradiation (only $75.6{ }^{\circ} \mathrm{C}$ for CdOx NPs) while the diesel index increases up to 60.3 (compared with 54.5 and 55.7 for raw diesel and after CdOx NPs treatment, respectively).

For both Cd diacetate and Cd NPs, the LHL irradiation appears to be more efficient than Xenon lamp (and UV systems); however, the DRS characteristics of Cd diacetate make the photocatalytic even

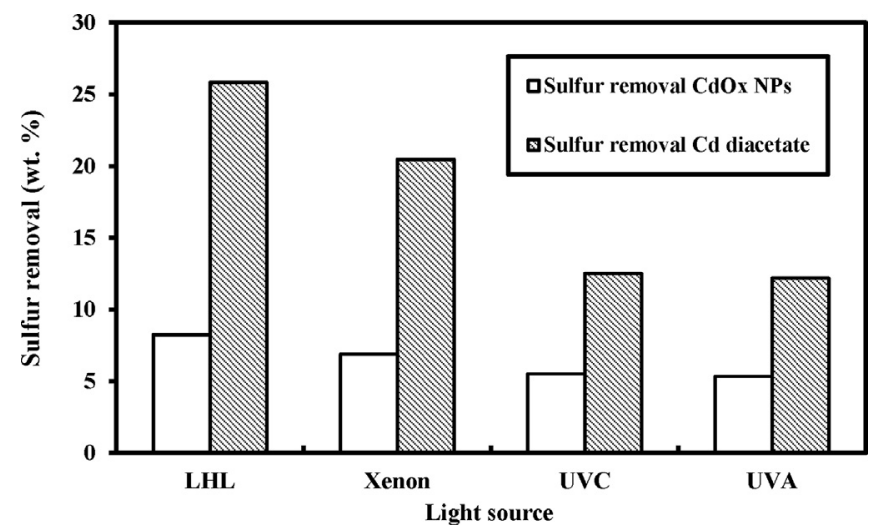

Fig. 5. Effect of the light source on sulfur removal (\%) using CdOx NPs and Cd diacetate photocatalysts ([sulfur]: $11500 \mathrm{ppm}$; for liquid photocatalyst: identical volume of diesel and molar $\mathrm{Cd}\left(\mathrm{CH}_{3} \mathrm{COO}\right)_{2}$ solution; for $\mathrm{Cd}$ NPs: the solid/liquid ratio was set to $7 \mathrm{~g} \mathrm{~L}^{-1}$; reaction time: $3 \mathrm{~h}$ at room temperature, using different irradiation systems; agitation speed: $500 \mathrm{rpm}$; separation: 45 -min settling time or filtration, respectively) Note: these data are representing the effective effect of light irradiation (the specific adsorption effect of the catalytic phase is not taken into account in the removal efficiency). 
more effective in photo-desulfurization. The catalytic activity is not only due to the metal but also its chemical state: acetate groups change the DRS properties and photocatalytic efficiency. Chong et al. reported the contribution of acetate groups for reducing the band-gap and then on the shift of the wavelength toward higher values (visible regions) (Chong et al., 2019). Moreover, the dispersion of the Cd complex in the diesel phase under agitation may allow a better availability of catalytic sites. Further studies are performed using visible irradiation lamps.

\subsubsection{Influence of volume ratio between liquid photocatalytic phase} and diesel

Fig. 6 shows the effect of the dosage of Cd diacetate on diesel desulfurization under visible irradiation (Xenon and LHL lamps); the volume ratio between liquid photo-catalyst phase and diesel is varied (i.e., $\mathrm{V}_{\mathrm{P} / \mathrm{D}}: 1 / 1,2 / 1,3 / 1$ and $4 / 1$ ). The diesel desulfurization yield is compared with the efficiency of the photo-catalyst (i.e., Cd NPs (Morshedy et al., 2016)). As expected from the previous section, the results obtained with both solid and liquid photo-catalysts confirm that the LHL lamp is more efficient than the Xenon lamp: the DRS properties of the photo-catalyst and the wavelength range of the respective lamps justify this result. The efficiency profiles follow the same trend (parallel curves with a shift of about 5\%-3\% efficiency). It is noteworthy that the removal of sulfur increases with increasing the amount of photo-catalyst from $1 / 1$ to $2 / 1 \mathrm{vol}$ ratio; however, above this limit ratio, increasing the amount of liquid photo-catalyst does not improve the efficiency of the process. This is consistent with previous results obtained on Cd NPs (Morshedy et al., 2016): increasing the amount of catalyst does not improve reaction performance above a limit value. A high concentration of catalytic sites increases the numbers of absorbed photons, but this photon absorption tends to reach an equilibrium. Zhao et al. observe similar trends while increasing the amount of $\mathrm{CdOx}$ in the reactor for ultrasound photocatalytic oxidative desulfurization of diesel (Zhao et al., 2018). Best experimental conditions correspond thus, for molar Cd diacetate solution, to a $2 / 1$ vol ratio between the aqueous and the organic phases. The aniline point and the diesel index are hardly changed by the amount of Cd diacetate and by the type of lamp: the variations do not exceed $2-3 \%$.

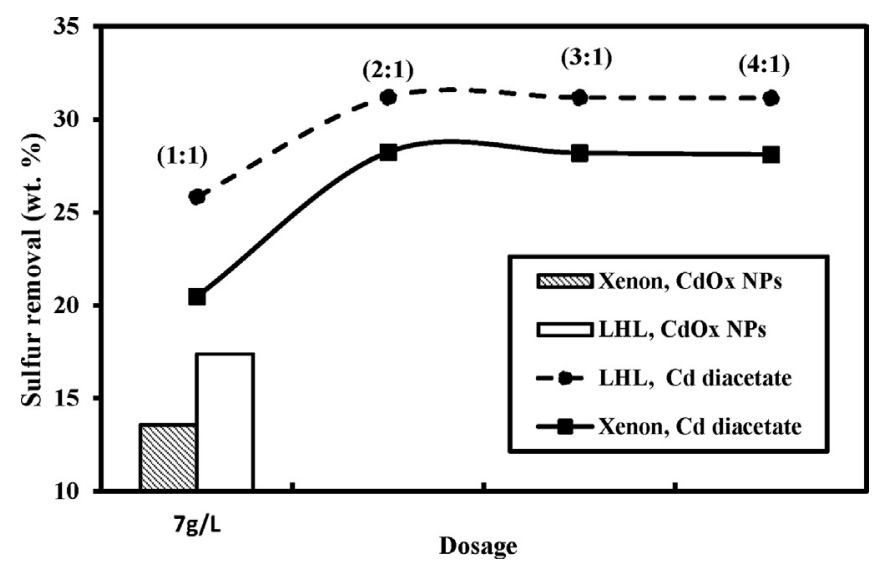

Fig. 6. Effect of $\left(\mathrm{Cd}\left(\mathrm{CH}_{3} \mathrm{COO}\right)_{2}\right.$ and $\left.\mathrm{CdOx} \mathrm{NPs}\right) /$ diesel feed stock on sulfur removal ([sulfur]: $11500 \mathrm{ppm}$; for liquid photocatalyst: variable volume ratio of molar $\mathrm{Cd}\left(\mathrm{CH}_{3} \mathrm{COO}\right)_{2}$ solution/diesel (1:1 to $\left.4: 1\right)$; for $\mathrm{Cd}$ NPs: the solid/liquid ratio was set to $7 \mathrm{~g} \mathrm{~L}^{-1}$; reaction time: $3 \mathrm{~h}$ at room temperature, under visible irradiation: Xenon or LHL lamp; agitation speed: $500 \mathrm{rpm}$; separation: 45-min settling time or filtration) Note: here the sulfur removal efficiency takes into account the contributions of both photocatalytic activity and adsorption.

\subsubsection{Effect of oxidizing agent $\mathrm{H}_{2} \mathrm{O}_{2}$}

The photocatalytic oxidative desulfurization is enhanced while oxidative conditions are improved: the presence of oxygen favors the photo-oxidation of DBT under visible light using CNT/Titania composite (Barmala et al., 2018). The addition of hydrogen peroxide is a widespread process for improving the performance of diesel desulfurization. Indeed, $\mathrm{H}_{2} \mathrm{O}_{2}$ is readily available (standard commercial product), "infinitively" solubility in water, with high rate effectiveness for $\left({ }^{\mathbf{0}} \mathrm{OH}\right)$ free radical production and well-known reactivity for "attacking" most organic substances (Amjed et al., 2017; Jiang et al., 2018; Keynejad et al., 2017; Wang et al., 2018; Zhang, L. et al., 2017a; Zhao et al., 2018). Fig. 7 compares the desulfurization yield (sulfur elimination efficiency) for both $\mathrm{Cd}$ diacetate and Cd NPs under visible light irradiation (LHL lamp) the use of different experimental conditions (volume ratio $\mathrm{Cd}$ diacetate/feed $/ \mathrm{H}_{2} \mathrm{O}_{2}$ for liquid photo-catalyst, Fig. 7a; the presence of $\mathrm{H}_{2} \mathrm{O}_{2}(30 \%, w / w)$ and acetic acid for Cd NPs, Fig. 7b). Fig. 7a shows that the introduction of $\mathrm{H}_{2} \mathrm{O}_{2}$ improves the efficiency of diesel desulfurization when using $\mathrm{Cd}$ diacetate. In the absence of the oxidant, sulfur removal reaches $31.2 \%$ (see Section 3.2.2.); in the presence of the oxidant ( $\mathrm{Cd}$ diacetate/diesel/ $\left.\mathrm{H}_{2} \mathrm{O}_{2}: 2 / 1 / 1\right)$ the efficiency increases up to $43.2 \%$; however, while increasing the dosage of $\mathrm{H}_{2} \mathrm{O}_{2}$, the efficiency of sulfur removal stabilizes around $42.8 \%$. The introduction of $\mathrm{H}_{2} \mathrm{O}_{2}$ improves the formation of free hydroxyl radicals $\left({ }^{\circ} \mathrm{OH}\right)$, which, in turn, enhances sulfur oxidation. However,
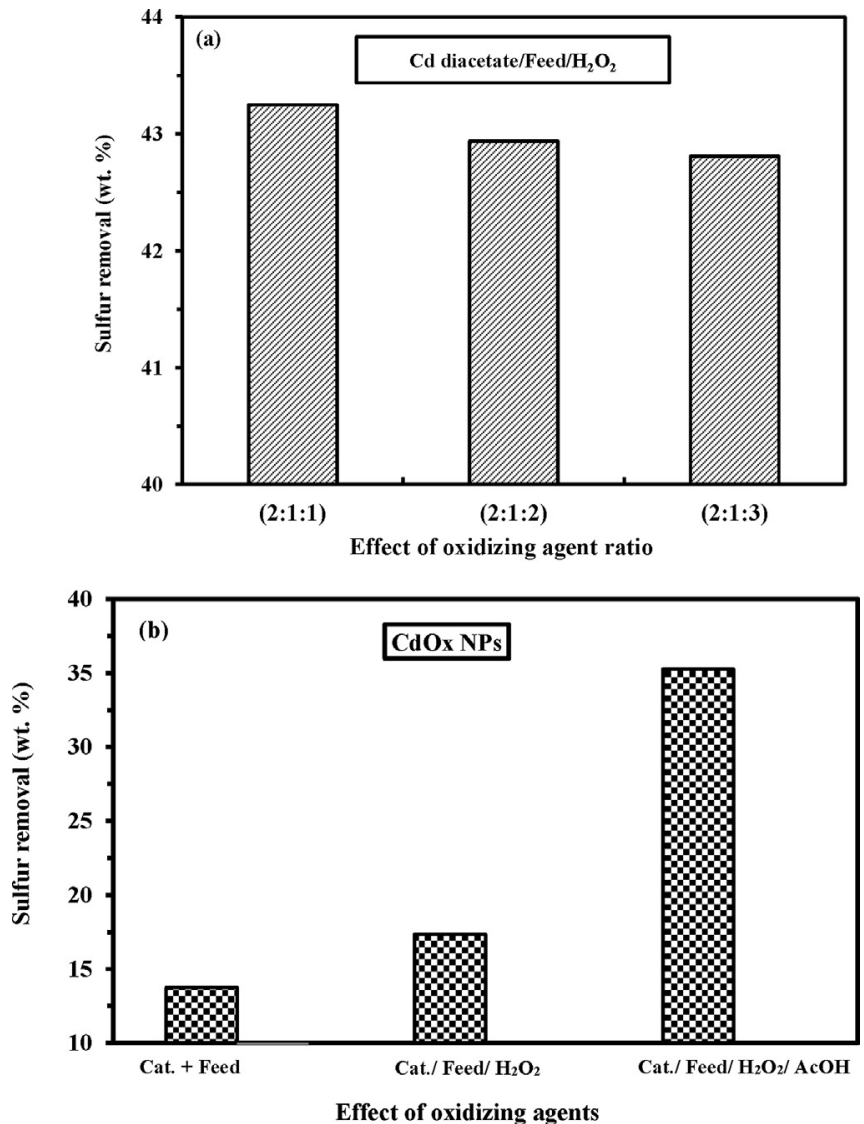

Fig. 7. Effect of oxidizing conditions $\left(\mathrm{H}_{2} \mathrm{O}_{2}\right.$ dosage, acetic acid presence) on sulfur removal using (a) Cd diacetate (Cd diacetate/Feed $/ \mathrm{H}_{2} \mathrm{O}_{2}(30 \%)=2: 1: 1$ to $2: 1: 3$ ), and (b) CdOx NPs (Feed $/ \mathrm{H}_{2} \mathrm{O}_{2}(30 \%) / \mathrm{AcOH}=1: 1: 1$ ) ([sulfur]: $11500 \mathrm{ppm}$; for liquid photocatalyst: variable volume ratio of molar $\mathrm{Cd}\left(\mathrm{CH}_{3} \mathrm{COO}\right)_{2}$ solution/diesel; for Cd NPs: the solid/liquid ratio was set to $7 \mathrm{~g} \mathrm{~L}^{-1}$; reaction time: $3 \mathrm{~h}$ at room temperature, under visible irradiation: LHL lamp; agitation speed: $500 \mathrm{rpm}$; separation: $45-\mathrm{min}$ settling time or filtration). 
an excess of oxidant can also contribute to the partial scavenging of hydroxyl radicals (Morshedy et al., 2016). Similar trends were found for the photocatalytic desulfurization of coal using $\mathrm{ZnO}$ nanocatalyst (Amjed et al., 2017). Zhao et al. reported that the optimum ratio was close to 1 between diesel feed and $\mathrm{H}_{2} \mathrm{O}_{2}$ when using mechanical stirring (Zhao et al., 2018); using ultrasound for processing the reaction does not require adding $\mathrm{H}_{2} \mathrm{O}_{2}$ : they explain that ultrasound accelerates the chemical reactions and,/or enhances the formation of radicals. On the other side, they reported that an excess of hydrogen peroxide (compared to fuel and sulfur contaminants) might cause side reactions, and then possible poisoning of the surface of catalysts.

Fig. 7b shows the effect of hydrogen peroxide on diesel desulfurization using Cd NPs: the feed $/ \mathrm{H}_{2} \mathrm{O}_{2}$ ratio is set to $1: 1$. The sulfur removal increases from $13.7 \%$ to $17.3 \%$. Based on the results obtained with $\mathrm{Cd}$ diacetate, another experiment was carried out in the presence of acetic acid (Feed $/ \mathrm{H}_{2} \mathrm{O}_{2} / \mathrm{AcOH}=1: 1: 1$ ) to evaluate the influence of the counterpart of $\mathrm{Cd}$ in the $\mathrm{Cd}$ diacetate photocatalyst. Morshedy et al. already reported the importance of acetic acid on photocatalytic desulfurization (Morshedy et al., 2016), they suggest that the presence of acetic acid introduces new radicals and,/or other oxidizing species. In the present case, the complementation of the reactive media with $\mathrm{AcOH}$ allows increasing sulfur removal up to $35.3 \%$. This increase means that though the desulfurization activity remains lower than for $\mathrm{Cd}$ diacetate (reference value: $43.2 \%$ ), the photocatalytic activity of $\mathrm{Cd}$ $\mathrm{NPs} / \mathrm{H}_{2} \mathrm{O}_{2}$ was doubled. The photocatalytic desulfurization takes advantage of both hydroxyl $\left({ }^{\circ} \mathrm{OH}\right)$ radicals and peracetic acid radicals (resulting from activation of acetic acid with $\mathrm{H}_{2} \mathrm{O}_{2}$ under irradiation) for promoting the oxidation of sulfur compounds (Morshedy et al., 2016).

The introduction of $\mathrm{H}_{2} \mathrm{O}_{2}$ improves aniline point and the diesel index up to the optimum volume ratio 2:1:1 ratio for Cd diacetate system reaching values as high as $84{ }^{\circ} \mathrm{C}$ and 66.7 , respectively. Above this volume ratio, the characteristics of desulfurized diesel remain unchanged.

In conventional photocatalytic processes, oxidized sulfur compounds are readily eliminated either by sorption on the surface of the used photo-catalyst (Gao et al., 2019; Liu et al., 2018; Zhang, W. et al., 2017) or by solvent extraction (Dharaskar et al., 2018; Morshedy et al., 2016). Practically, under selected experimental conditions, the biphasic liquid system " $\mathrm{Cd}\left(\mathrm{CH}_{3} \mathrm{COO}\right)_{2} / \mathrm{diesel} / \mathrm{H}_{2} \mathrm{O}_{2}$ " shows higher sulfur removal than the heterogeneous system "CdOx $\mathrm{NPs} /$ diesel $/ \mathrm{H}_{2} \mathrm{O}_{2} / \mathrm{AcOH}$ ". These results confirm the promises of liquid $\mathrm{Cd}$ diacetate for photocatalytic desulfurization of diesel.

It is noteworthy that the conditions selected for the comparison of the two systems are substantially different. Despite the excess of the oxidizing agent in the case of CdOx NPs compared with photo liquid catalyst, the efficiency is much higher for Cd diacetate hydrate catalyst. This is another evidence of the superiority of the photo liquid catalyst against conventional CdOx NPs.

\subsubsection{Desulfurization kinetics}

The desulfurization kinetics are represented on Fig. 8 under optimized experimental conditions (LHL lamp irradiation; volumetric ratio $\mathrm{Cd}$ diacetate/diesel $/ \mathrm{H}_{2} \mathrm{O}_{2}: 2: 1: 1$; agitation speed: $500 \mathrm{rpm}$; [ $\left.\mathrm{S}_{0}\right]: 11500 \mathrm{ppm}$; room temperature). Two steps characterize the kinetics: (a) fast initial step within the first $30 \mathrm{~min}$ of contact (about $77 \%$ of total sulfur removal), and (b) a much slower step, from $15 \mathrm{~min}$ to $2 \mathrm{~h}$ or contact.

Pseudo-first order rate equation (PFORE), pseudo-second-order rate (PSORE), and Langmuir-Hinshelwood (LSH) equations have been unsuccessfully tested for modeling the kinetic profiles. The PFORE was appropriate for the modeling of the sorption of the thiophene compounds on $\mathrm{TiO}_{2} / \mathrm{SiO}_{2}$ under irradiation (Miao et al., 2015), and the

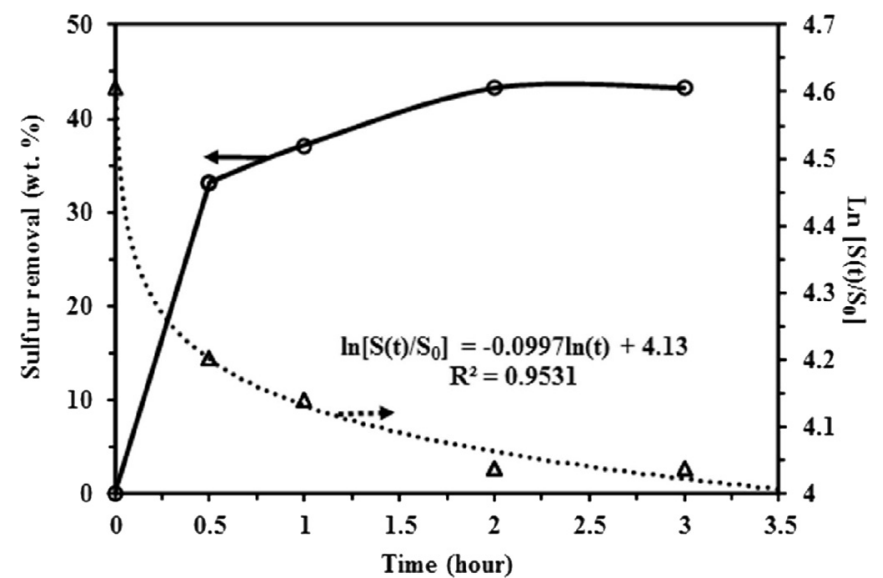

Fig. 8. Effect of reaction time on sulfur removal (\%) using $\mathrm{Cd}$ diacetate photocatalyst (Cd diacetate/Feed $/ \mathrm{H}_{2} \mathrm{O}_{2}(30 \%)=2: 1: 1$ : conditions; room temperature; settling time: $45 \mathrm{~min}$; under LHL irradiation).

photo-oxidation of dibenzothiophene on CNT/titania composites (Barmala et al., 2018). In the dark, the kinetic profile for sulfur removal was also controlled by a pseudo-first-order rate (see Section 3.3.1.). Here the coexistence of different mechanisms (sorption, photooxidation) and reagents (diesel, hydrogen peroxide) does not allow readily modeling kinetic profiles.

A contact time of $2 \mathrm{~h}$ is sufficient for achieving the equilibrium with a sulfur removal close to $43 \%$. The aniline point and the diesel index increase with reaction time and reach up to $84^{\circ} \mathrm{C}$ and 66.7, respectively.

\subsubsection{Solvent extraction}

A good method for increasing the desulfurization rate consists of introducing a complementary solvent extraction step (Jiang et al., 2020). This step can be performed using acetonitrile at controlled temperature (i.e., $50^{\circ} \mathrm{C}$ ). Fig. 9 explores the effect of varying volumetric ratios between acetonitrile and reagent media (including $\mathrm{Cd}$ diacetate phase, diesel feed, and $\mathrm{H}_{2} \mathrm{O}_{2}$ ). The addition of the acetonitrile phase strongly increases desulfurization efficiency: from $43 \%$ (see Section 3.3.4.) to 67\% (at 0.5:1 volumetric ratio) and progressively up to $98.5 \%$ (at 2:1 volumetric ratio). Previous investigations showed that the application of acetonitrile directly on the feedstock

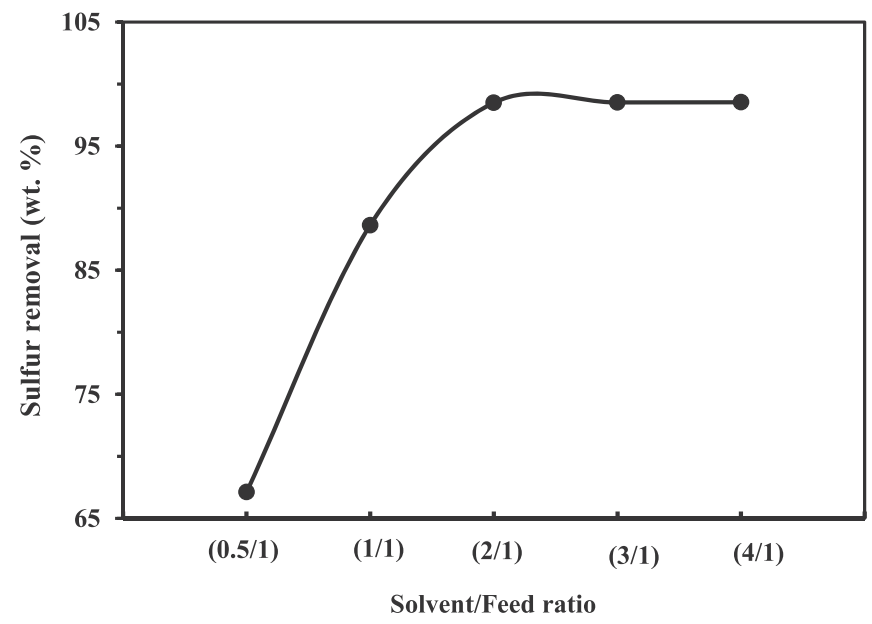

Fig. 9. Effect of solvent/feed ratio on sulfur removal ( $\mathrm{Cd}$ diacetate/Feed $/ \mathrm{H}_{2} \mathrm{O}_{2}$ $(30 \%)=2: 1: 1$; room temperature; stirring speed: $500 \mathrm{rpm}$; settling time: $45 \mathrm{~min}$; under LHL irradiation; separation at room temperature with Solvent/feed ratio: 0.5:1 to $4: 1)$. 
only removed a weak fraction of sulfur (about 36\%) because of the presence of refractory divalent sulfur compounds (Morshedy et al., 2016). However, after the oxidation of the sulfur compounds with CdOx NPs or Cd diacetate hydrate, in the presence of oxidizing agents, acetonitrile removes the most polar sulfur compounds; the removal of tetravalent and hexavalent sulfur compounds is confirmed by FTIR analysis on a real feedstock. Increasing the volumetric ratio does not change the desulfurization yield. The aniline point and the diesel index also reach an optimum at $91{ }^{\circ} \mathrm{C}$ and 76.1, respectively.

With a 4:1 volumetric ratio between the solvent phase and the suspension of CdOx NPs (at a dosage of $7 \mathrm{~g} \mathrm{~L}^{-1}$, in a mixture of diesel feed, $\mathrm{H}_{2} \mathrm{O}_{2}$, and acetic acid), the desulfurization yield (i.e., 97.7\%) comes closer to the performances reached with $\mathrm{Cd}$ diacetate.

The successful oxidation of sulfur-based compounds enhances the global desulfurization yield. Under selected experimental conditions, very high levels of desulfurization can be reached with excellent properties of treated diesel (in terms of both aniline point, about $91^{\circ} \mathrm{C}$, and diesel index, about 76). Cadmium diacetate shows higher desulfurization performance; this confirms the promising concept of this active liquid photo-catalyst.

\subsubsection{Sunlight induced photocatalytic desulfurization}

The competitiveness (and finally, its potential application) depends on cost parameters, especially energy consumption. The results obtained at preceding sections have demonstrated the superiority of visible light for the desulfurization of diesel. This is an essential criterion since it is possible to directly test the reaction under sun exposure (replacing LHL lamp with sun exposure for decreasing operational costs). The average intensity of the solar energy, which depends on localization and season, has been evaluated to $1371 \mathrm{Wm}^{-2}$ (Morshedy et al., 2016). Table 1 summarizes the characteristics of the treated diesel using either CdOx NPs or cadmium diacetate systems under optimized conditions (contact time: $5 \mathrm{~h}$ ). Other experimental conditions consist of:

Cd diacetate system: Cd diacetate/Feed $/ \mathrm{H}_{2} \mathrm{O}_{2}(30 \%)=1: 2: 1$ and solvent/feed ratio $=2: 1$

CdOx NPs: dosage $=7 \mathrm{~g} \mathrm{~L}^{-1}$; Feed $/ \mathrm{H}_{2} \mathrm{O}_{2}(30 \%) / \mathrm{AcOH}=1: 1: 1$ : and solvent/feed ratio $=4: 1$

The process includes the acetonitrile extraction step. Though the two systems show high desulfurization performance, Cd diacetate shows superior efficiency (99.4\% against $98.0 \%$ yields). Residual amounts of sulfur in treated diesel reach $234.6 \mathrm{ppm}$ for CdOx NPs and much lower concentration for liquid photo-catalyst (with a residual concentration close to $65 \mathrm{ppm}$ ). These values remain

Table 1

Rate of diesel fuel desulfurization under sunlight exposure, with subsequent solvent extraction.

\begin{tabular}{|c|c|c|c|}
\hline \multirow[t]{2}{*}{ Characterization } & \multirow{2}{*}{$\frac{\text { Diesel }}{(\text { raw })}$} & \multicolumn{2}{|c|}{$\begin{array}{l}\text { CdOx (time: } 10.00 \text { a.m. - } \\
\text { 3.00pm) }\end{array}$} \\
\hline & & $\mathrm{CdOx}$ & Cd diacetate \\
\hline Yield (wt. \%) ${ }^{\mathrm{a}}$ & - & 80.78 & 80.02 \\
\hline Refractive index @ $20^{\circ} \mathrm{C}$ & 1.4866 & 1.4570 & 1.4560 \\
\hline Density @ $20^{\circ} \mathrm{C}\left(\mathrm{gm} / \mathrm{cm}^{3}\right)$ & 0.8575 & 0.8242 & 0.8200 \\
\hline Sulfur content (ppm) & 11500 & 234.6 & 65.5 \\
\hline S Removal (wt. \%) & - & 98.0 & 99.4 \\
\hline Aniline point $\left({ }^{\circ} \mathrm{C}\right)$ & 74.0 & 91.4 & 91.8 \\
\hline Diesel index & 54.5 & 77.8 & 79.8 \\
\hline
\end{tabular}

a The weight of the extracted phase from acetonitrile solvent and it is equal to (the weight of the product after solvent extraction step) divided over (the weight of original feedstock) X 100 higher than the requested levels for use for road transport and domestic fuel use (i.e., 10-15 ppm), but this can be considered a competitive pre-treatment, especially while using $\mathrm{Cd}$ diacetate system.

\subsubsection{Regeneration of the used solvent}

To reduce the operational costs, it is necessary for evaluating the possibility to regenerate and recycle the solvent phase (acetonitrile). This regeneration was carried out by atmospheric distillation. The quality of the regeneration of the solvent was measured by the values of its refractive index (RI) and its density along with three successive recycling steps. Table AM3 reports the characteristics of the treated diesel (for both CdOx NPs and Cd diacetate systems) and the properties of the solvent at each step. These results confirm the high stability of the solvent and treatment performances and the high effectiveness of the global process.

\subsubsection{Sustainability and reusability issues on CdOx NPS}

The photo-desulfurization of diesel produces sub-products such as sulfoxides and sulfones (Ali et al., 2006; Duarte et al., 2011; Zhao et al., 2018), which, in turn, contribute to catalyst poisoning (Wang and You, 2016), this is especially important in the case of a heterogeneous catalyst such as CdOx NPs. Using a homogeneous system like $\mathrm{Cd}$ diacetate is advantageous for preventing this inactivation by sub-product deposition. The presence of such compounds is confirmed by EDX analysis. TEM images show a substantial change in the morphology of the spent catalyst after the desulfurization process (Figure AM11, see AMS). Figure AM12 (see AMS) shows the comparison of the FTIR spectra of the feed, the feed after CdOx NPs photocatalytic desulfurization, and finally, after solvent extraction. Briefly, sulfones and sulfoxides are expected to appear at $1295 \mathrm{~cm}^{-1}$ (asymmetric $\mathrm{S}=\mathrm{O}$ stretching vibration) and $1147 \mathrm{~cm}^{-1}$ (symmetric $\mathrm{S}=\mathrm{O}$ stretching vibration) (Morshedy et al., 2016). Here, this is confirmed by the appearance of two peaks at $1273 \mathrm{~cm}^{-1}$ and $1138 \mathrm{~cm}^{-1}$ after photocatalytic desulfurization. These two peaks are disappearing after solvent extraction: acetonitrile efficiently removed the sub-products of the desulfurization process (sulfones and sulfoxides). A small shift is observed for the $\mathrm{CH}_{3}$ bending vibration (from 1365 to $1378 \mathrm{~cm}^{-1}$ ), together with the disappearance of the peak at $1514 \mathrm{~cm}^{-1}$ (assigned to $\mathrm{C}=\mathrm{C}$ bonds). These changes may be explained by the breaking of some of these bonds during photocatalysis or by the removal of relevant molecules during the solvent extraction step (Sae-Ma et al., 2010).

The significant advantage of using $\mathrm{Cd}\left(\mathrm{CH}_{3} \mathrm{COO}\right)_{2}$ in the desulfurization process consists of the possibility to reuse the catalyst without loss in photo-activity compared with the solid photocatalyst (i.e., CdOx NPs). Indeed, the decrease in desulfurization activity is much faster on solid catalyst due to the progressive deposition of sulfur compounds on the surface of the material. Also, besides the complementary extraction process reveals more efficiency for liquid photo-catalyst ( $\mathrm{Cd}$ diacetate). Fig. $4 \mathrm{~b}$ shows the Raman analysis for the spent $\mathrm{Cd}$ based diacetate and it was identical to the freshly prepared sample confirming the molecular structure for the used catalyst after the process.

\subsubsection{Regeneration of $\mathrm{Cd}\left(\mathrm{CH}_{3} \mathrm{COO}\right)_{2}$ and $\mathrm{CdOx} \mathrm{NPS}$}

The aqueous phase containing the liquid photo-catalyst $(\mathrm{Cd}$ diacetate) was recycled eight times. The refractive index (RI) was tested after regeneration to ensure the activity and purity of photoliquid; the reference value for $\mathrm{Cd}\left(\mathrm{CH}_{3} \mathrm{COO}\right)_{2} * \mathrm{H}_{2} \mathrm{O} \mathrm{RI}$ is 1.3435 . This value remains stable for five cycles. After the fifth cycle, the RI slightly increases (up to $1.3436,1.3437$, and 1.3439 , at the sixth, seventh, and eighth cycles, respectively). In the case of the soild heterogeneous photo-catalyst, spent CdOx NPs were regenerated using three successive washing steps with benzene followed by 
ethanol and demineralized water. The washed catalyst was dried and finally calcined at $500{ }^{\circ} \mathrm{C}$ to ensure the removal of adsorbed sulfur.

$\mathrm{Cd}\left(\mathrm{CH}_{3} \mathrm{COO}\right)_{2} * \mathrm{H}_{2} \mathrm{O}$ could be reused seven times with a little decrease in photo desulfurization activity (about 1.7\% decrease in Sremoval efficiency after seven cycles) (Fig. 10). This stability indicates that $\mathrm{Cd}\left(\mathrm{CH}_{3} \mathrm{COO}\right)_{2} * \mathrm{H}_{2} \mathrm{O}$ has an excellent recycling performance. While increasing the number of cycles, the S-removal decreased from $98.5 \%$ to $95.1 \%$; this may be attributed to the accumulation of some sulfur compounds in the $\mathrm{Cd}\left(\mathrm{CH}_{3} \mathrm{COO}\right)_{2} * \mathrm{H}_{2} \mathrm{O}$ layer after seven cycles (Table 2).

\subsection{Tentative mechanisms involved in the photo-oxidation of sulfur compounds from diesel}

To understand the mechanism, some tests should be achieved:

\section{a) The radicals trapping test}

The radicals trapping test was carried out to understand the photocatalytic mechanism. Three separate photocatalytic experiments containing three different scavengers are checked to identify the source of active species in the reaction. Isopropyl alcohol (IPA) is a quencher for ${ }^{\circ} \mathrm{OH}$ free radicals, p-benzoquinone (p-BQ), is a quencher for holes and ammonium oxalate is a quencher for superoxide radicals (Pelaez et al., 2016; Torki and Faghihian, 2017).

Figure AM13 (see AMS) confirms that the DBT is completely
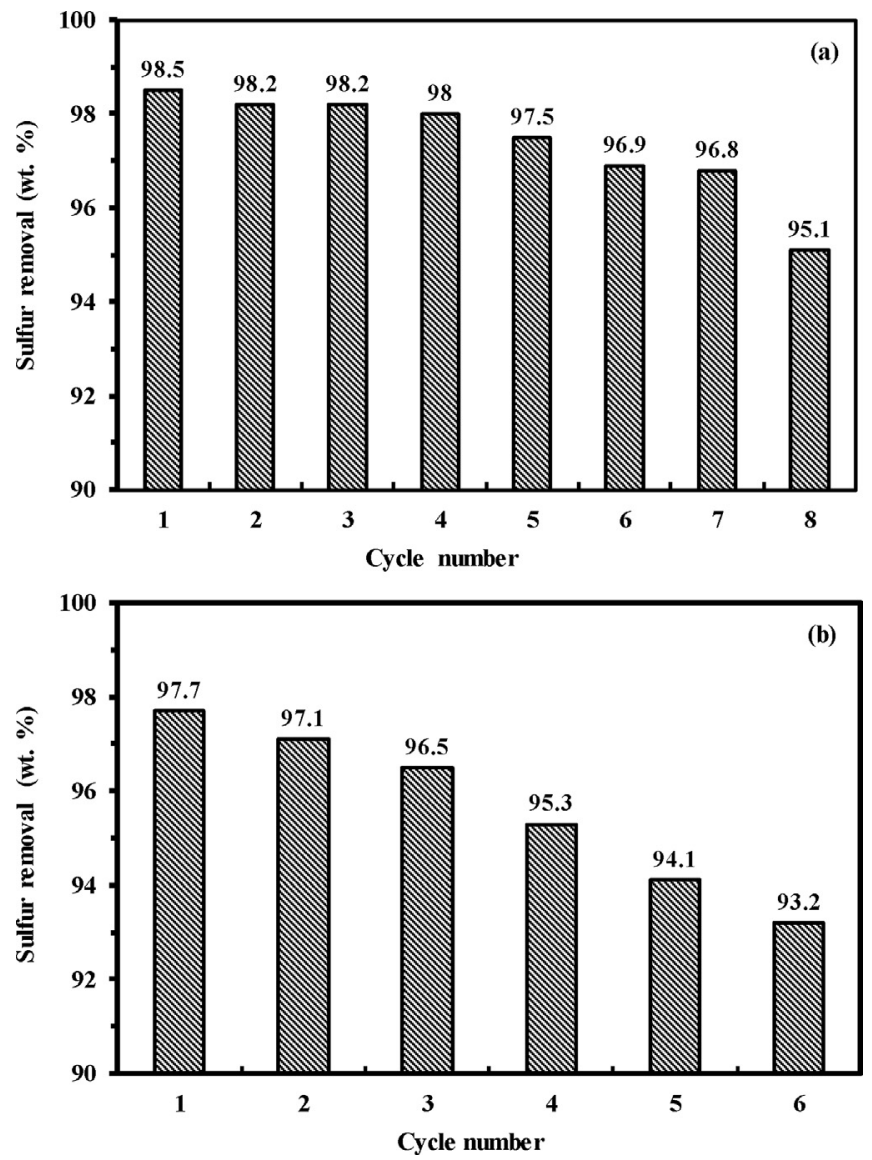

Fig. 10. Effect of catalyst recycling on desulfurization efficiency: (a) Cd diacetate, (b) CdOx NPs (Reaction Conditions: light: LHL; reaction time: $2 \mathrm{~h}$; room temperature; $\mathrm{Cd}\left(\mathrm{CH}_{3} \mathrm{COO}\right)_{2} /$ Feed $/ \mathrm{H}_{2} \mathrm{O}_{2} ; 2: 1: 1$ and $\mathrm{S} / \mathrm{F}=2: 1$; for CdOx NPs: catalyst dosage: $7 \mathrm{~g} \mathrm{~L}-1$; Feed $/ \mathrm{H}_{2} \mathrm{O}_{2} / \mathrm{AcOH}=1: 1: 1$; and $\mathrm{S} / \mathrm{F}=4 / 1$ ). converted without scavenger by using both catalysts (CdOx NPs and $\mathrm{Cd}$ diacetate) separately. In the case of IPA, the rate of conversion decrease for both catalysts, but the little increase for diacetate compared to CdOx NPs is due to not only the holes of Cd diacetate plays a role but also, due to its activity acting as a solvent. The same as in the case of p-benzoquinone but, the rate of conversion is very low, which ensures the vital role of holes to convert the DBT and also to cause the dissociation of hydrogen peroxide via the electrons in the conduction band during excitation. The concentration of DBT after each test is measured on the UV-spectrophotometer model V-570 manufactured by JASCO (Japan). While in the case of ammonium oxalate scavenger, the conversion is complete for the two catalysts. These results prove that both $\mathrm{h}+$ and ${ }^{\circ} \mathrm{OH}$ free radical play an essential role in the reaction while $\mathrm{O}_{2}^{-}{ }^{\bullet}$ superoxide radicals have no role.

The rate of extraction and oxidation of DBT during the desulfurization of model oil (500 ppm of DBT) by photo liquid Cd diacetate was investigated by GC analysis. Retention times for DBT and DBT sulfone were determined through GC analysis of standard solutions of DBT and DBT sulfone in toluene. Sulfur-based compounds, including DBT (present in the fuel) and DBT sulfone (oxidized product of the desulfurization process), were extracted from the photo liquid layer using toluene before being analyzed by GC. Figure AM14 (see AMS) shows an illustration of the kinetics of DBT oxidation to DBT sulfone. Besides, Figure AM15 (see AMS) illustrates both products and reactive species of sulfur compounds in diesel fuel during the process by using GC-FPD analysis for I) Diesel feedstock, II) Diesel feedstock after photo-catalytic oxidation with using $\mathrm{Cd}\left(\mathrm{CH}_{3} \mathrm{COO}\right)_{2}$ as the liquid photo-catalyst, and III) After solvent extraction of II) with acetonitrile $\mathrm{CH}_{3} \mathrm{CN}$. The Figure confirms the following:

I) Discuss nearly all of the sulfur compounds present in the diesel feedstock, which will be removed after photocatalytic oxidation under visible light by using Cd diacetate at optimum condition followed by the solvent extraction step by $\mathrm{CH}_{3} \mathrm{CN}$.

II) shows a significant part of the sulfur compounds such as (DBT) and its derivatives especially (MDBT), (DMDBT) and (TMDBT) has been decreased to a lower level as identified by comparing their peak before and after catalytic photooxidation, while the other part was converted into oxidized corresponding sulfone like $\mathrm{DBTO}_{2}, \mathrm{MDBTO}_{2}, \mathrm{DMDBTO}_{2}$ and $\mathrm{TMDBTO}_{2}$ as indicated by the occurrence of new peaks at higher retention time (Ma et al., 2002; Otsuki et al., 2000).

III) proves the absence of oxidized sulfone (more polarized) after the solvent extraction step. Low detected insoluble sulfone derivatives appear at higher retention time (Shiraishi et al., 2002). FBD identification of standard sulfur compounds was listed in Table AM5 (see AMS).

b) Confirmation of the generation of ${ }^{\circ} \mathrm{OH}$ free radicals during the photocatalytic oxidative reaction.

As literature, terephthalic acid is inactive fluorescent reacted with the ${ }^{\circ} \mathrm{OH}$ radicals, which generate from the reaction to produce 2-hydroxyterephthalic acid, which is a fluorescent active molecule ( $\lambda$ at $\sim 425 \mathrm{~nm}$ ) Scheme 1 .

To detect the ${ }^{\circ} \mathrm{OH}$ radicals, terephthalic acid was used as a probe molecule. In a typical run, $0.35 \mathrm{~g}$ of CdO NPs catalyst was added in $50 \mathrm{ml}$ aqueous solution of $(0.002 \mathrm{~g}, 0.5 \mathrm{mmol}$ terephthalic acid and $0.002 \mathrm{~g}, 2 \mathrm{mmol}$ of $\mathrm{NaOH}), 500 \mathrm{ppm}$ of DBT and $0.02 \mathrm{~mol}$ of hydrogen peroxide. The mixture was kept under magnetic stirring in the dark for $1 \mathrm{~h}$. Then, it was irradiated with a linear Halogen lamp (visible light), and CdO NPs was separated by centrifugation. A 
Table 2

Optimization of the global process of photocatalytic desulfurization of diesel sample.

\begin{tabular}{|c|c|c|c|}
\hline & Parameter & CdOx NPs & Cd diacetate photo-liquid \\
\hline Desulfurization & Irradiation mode & Linear halogen lamp LHL, $500 \mathrm{~W}$ & Linear halogen lamp LHL, $500 \mathrm{~W}$ \\
\hline Operating & Irradiation time & $3 \mathrm{~h}$ & $2 \mathrm{~h}$ \\
\hline \multirow[t]{5}{*}{ Parameters } & Processing time & 45 min for Settling & 45 min for Settling \\
\hline & Catalyst dosage/Feed & $7 \mathrm{~g} \mathrm{~L}^{-1}$ & $(2: 1)(\mathrm{v} / \mathrm{v})$ \\
\hline & Oxidizing agents & Feed/H2O2/AcOH (1:1:1) & Feed/Cd diacetate/H2O2 (1:2:1) \\
\hline & Solvent $(\mathrm{CH} 3 \mathrm{CN}) /$ Feed ratio & $4 / 1$ & $2 / 1$ \\
\hline & Solvent extraction conditions $\left(50^{\circ} \mathrm{C}\right)$ & $\begin{array}{l}\text { Mixing (45 min) at } 500 \mathrm{rpm} \text { Settling } \\
(45 \mathrm{~min})\end{array}$ & $\begin{array}{l}\text { Mixing ( } 45 \mathrm{~min}) \text { at } 500 \mathrm{rpm} \text { Settling } \\
(45 \mathrm{~min})\end{array}$ \\
\hline \multirow{8}{*}{$\begin{array}{l}\text { Treatment performance - Quality of treated } \\
\text { diesel }\end{array}$} & Yield (wt. \%)* & 82.75 & 81.21 \\
\hline & S removal (\%) & 97.7 & 98.5 \\
\hline & Refractive index $\left(20^{\circ} \mathrm{C}\right)$ & 1.4575 & 1.4569 \\
\hline & Density $\left(20^{\circ} \mathrm{C}\right)\left(\mathrm{gm} / \mathrm{cm}^{3}\right)$ & 0.8289 & 0.8278 \\
\hline & Aniline & 90.80 & 91.00 \\
\hline & Diesel Index & 75.49 & 76.07 \\
\hline & $\begin{array}{l}\text { Limit recycling number for } \\
\text { desulfurization }\end{array}$ & 6 times $(97.7 \rightarrow 93.2)$ & 8 times $(98.5 \rightarrow 95.1)$ \\
\hline & Recycling of acetonitrile & Effective (at least 2 cycles) & Effective (at least 2 cycles) \\
\hline
\end{tabular}

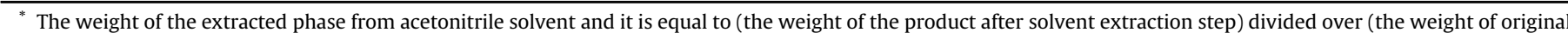
feedstock) X 100.

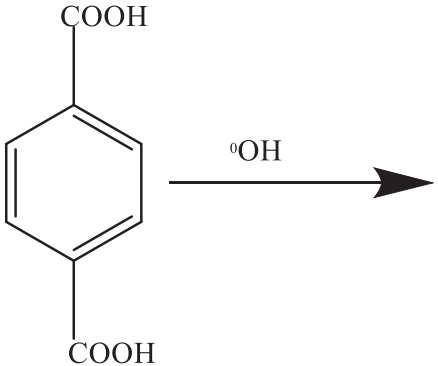

Terephthalic Acid

(Inactive-fluorescent)<smiles>O=C(O)c1ccc(C(=O)O)c(O)c1</smiles>

2-hydroxyterephthalic Acid (Active-fluorescent $=\mathbf{4 2 5} \mathrm{nm}$ )

Scheme 1. The reaction of terephthalic acid with the hydroxyl radicals.

spectrofluorometer analyzed the supernatant. The same experiment is repeated except CdOx NPs was replaced by $40 \mathrm{ml}$ of $\mathrm{Cd}$ diacetate photo-liquid.

Figure AM16 (see AMS) shows zero fluorescence intensity at the beginning of the experiment. However, the fluorescent intensity appears for the two photo-catalysts ensuring the presence of 2hydroxyterephthalic acid at $425 \mathrm{~nm}$ (Pi et al., 2016; Sher Shah et al., 2014). This experimental result proves that the two catalysts generate ${ }^{\circ} \mathrm{OH}$ free radicals in the reaction.

Depending on the previous experiments, Figure AM17 (see AMS) shows a tentative scheme describing the catalytic process of photo-chemical desulfurization. Photo-catalyst can absorb photons at fixed wavelength; peripherical excited electrons move from the ground state (LUMO) to the conduction band (HOMO) leaving charged holes $(h+)$ in the valence band (Eq. (3)) (Morshedy et al., 2016):

Photocatalyst $+h \nu \rightarrow\left(h^{+}\right)+\left(e^{-}\right)$

The holes act as an oxidizing agent that takes part in the oxidation reactions of sulfur compounds (Eq. (4)).

Photocatalyst $\left(h^{+}\right)+$Sulfur present in diesel fuel $\rightarrow$ Photocatalyst + Oxidation products

The addition of $\mathrm{H}_{2} \mathrm{O}_{2}$ generates $\left({ }^{\circ} \mathrm{OH}\right)$ free radicals (Eqs. (5) and (6)), which directly oxidize the sulfur compounds in the diesel

feedstock (Eq. (7))

$\mathrm{H}_{2} \mathrm{O}_{2}+h v \rightarrow 2{ }^{\circ} \mathrm{OH}$

Photocatalyst $\left(\mathrm{e}^{-}\right)+\mathrm{H}_{2} \mathrm{O}_{2} \rightarrow{ }^{\circ} \mathrm{OH}+{ }^{-} \mathrm{OH}$

${ }^{\circ} \mathrm{OH}+$ Sulfur present in diesel fuel $\rightarrow$ Oxidation products

In the presence of acetic acid, part of $\left({ }^{\circ} \mathrm{OH}\right)$ free radicals convert acetic acid to peracetic acid (Eq. (8)). This conversion is enhanced by the presence of the catalyst. This strong oxidizing agent enhances the rate of sulfur oxidation (Eq. (9)) (More and Gogate, 2019; Tumula et al., 2012):

${ }^{\circ} \mathrm{OH}+\mathrm{CH}_{3} \mathrm{COOH} \rightarrow\left[\mathrm{CH}_{3} \mathrm{COOO} * \mathrm{H}\right]$

$\left[\mathrm{CH}_{3} \mathrm{COOO} * \mathrm{H}\right]+$ Sulfur present in diesel fuel $\rightarrow$ Oxidation products

These polar compounds can easily remove through the solvent extraction step (Morshedy et al., 2016).

\subsection{Suggested optimum process for desulfurization of diesel using CdOx NPs and Cd diacetate photo-catalysts}

Table AM4 in the additional material section, containing the recent research of photocatalytic oxidative desulfurization (Juliao et al., 2019; Keynejad et al., 2017; Morshedy et al., 2016; Wang, C. et al., 2014b; Zhao et al., 2018; Zhu et al., 2015; Zhu et al., 2014), including desulfurization rates and other vital parameters. While Table 2 summarizes the best experimental conditions for the global photocatalytic desulfurization process using either CdOx NPs or Cd diacetate photo liquid and the relative treatment performances. The photo-liquid catalyst ( $\mathrm{Cd}$ diacetate) shows very promising perspectives for diesel desulfurization, especially compared with CdOx NPs. The photocatalytic activity of Cd-based structures mainly depends on the excitation-relaxation action of the most outer shell electron of $\mathrm{Cd}$ atom. However, the attached atoms to the Cd may play a crucial role in improving its photocatalytic performance. In the case of using the Cd acetate compound, as a photocatalyst, the acetate group could take part in the photoactivity. Notably, the valency electrons of $\mathrm{C}$ and $\mathrm{O}$ atoms could be excited by absorbing the illuminating irradiation forming new centers of 
electron-hole pairs. Therefore, an increased photocatalytic attack by $\mathrm{Cd}$ acetate toward the proposed substrate could be energetically undertaken. Additionally, the acetate group has a high electron density due to the presence of 2 carbon and 20 atoms. Thus, the overlap between the electron clouds of these four atoms and the valence band electrons of the $\mathrm{Cd}$ atom could significantly reduce its bandgap. Moreover, this overlap could, in turn, result in the delay of recombination between the excited electrons (highest occupied molecular orbitals, HOMO) of Cd and its generated holes (lowest unoccupied molecular orbitals, LUMO), this was confirmed by PL study Figure AM6 in the additional material section. This higher efficiency can be explained by the double effect of the immiscible liquid in terms of solvent extraction facilities but also by the presence of lone pairs on acetate groups that act as electron scavenger or trapper. A similar interpretation was already reported for the enhancement of the photocatalytic activity of $\mathrm{TiO}_{2}$ nanoparticles by impregnation with ionic-liquid ( $\mathrm{Hu}$ et al., 2010), and $\mathrm{BiPO}_{4} /$ ionic liquid system (Jing et al., 2015; Lv et al., 2015).

The two catalysts have a limited impact on the metal content in the treated oil (at least considering Cd). Indeed, CdOx NPs can be readily recovered from treated feedstock by filtration. The collected particles were treated with acetonitrile during the solvent extraction step and then carefully washed (i.e., 4 times) with demineralized water. After centrifugation, the solid was dried using $\mathrm{CaCl}_{2}$ salt. In the case of a photo liquid catalyst, the immiscibility of the two phases limits the release of $\mathrm{Cd}$ into the treated feedstock. Complementary analyses, performed on diesel feedstock before and after treatment with CdOx NPs and photo-liquid catalyst, included acid mineralization (sulfuric acid/nitric acid mixture) under microwave irradiation (ASTM 874), and Cd quantification using atomic absorption spectroscopy (Analytik Jena Zeenit $700 \mathrm{P}$, Jena, Germany). These experiments show that both feedstock and the diesel desulfurized with photo-liquid catalysts are free from $\mathrm{Cd}$, while the treatment with CdOx NPs induces the release of cadmium (about $60 \mu \mathrm{g}$ in $30 \mathrm{~mL}$ of diesel sample; i.e., concentration close to $2 \mathrm{mg} \mathrm{L}^{-1}$ ). This confirms the superiority of photo-liquid immiscible catalysts in terms of cadmium release compared with more conventional CdOx NPs.

\section{Conclusions and future prospects}

A promising innovative catalyst was synthesized under the immiscible liquid form ( $\mathrm{Cd}$ diacetate) for the photocatalytic desulfurization of sulfur-containing diesel; its performances were compared to mixed-phase CdOx NPs. The choice of $\mathrm{Cd}$ based structures as photo-catalyst is due to several reasons that are related to both costs and specific features of $\mathrm{Cd}$ as an element. First, the Cd precursors are of low-cost materials. Thus, the fabrication of photo-catalyst based on Cd is a cost-effective solution. The second reason is that $\mathrm{Cd}$ is an effective photo-catalyst in the region of visible light. Therefore, low operational costs can be provided through the designated process for Cd-based photo-catalysts.

Several techniques were used for characterizing the materials in terms of structure and texture, chemical properties, photoluminescence activity. Testing their efficiencies for photocatalytic removal of sulfur shows that visible light is sufficient for achieving good desulfurization. The effect of a series of parameters (dosage, presence of acetic acid for CdOx NPs, oxidizing agents such as $\mathrm{H}_{2} \mathrm{O}_{2}$ ) was investigated to define optimal conditions for photocatalysis. Visible light is sufficient for achieving high rates of removal; this makes the process competitive. In a second step, a solvent extraction process was introduced in the global process for improving the yield of desulfurization. Very high levels of decontamination are achieved: higher than $99.4 \%$ for Cd diacetate under sunlight, higher than the levels reached with CdOx NPs. The properties of treated diesel (aniline point close to $91.8{ }^{\circ} \mathrm{C}$, and diesel point higher than 79.8) confirm the capacity of the system to produce high-quality fuels. Another advantage concerns the recycling of the catalyst: liquid photo-catalyst allows maintaining high levels of efficiency for more prolonged use than solid nanoparticles. Indeed, the liquid photo-catalyst requires a lower solvent/feed ratio compared to CdOx NPs. The solvent is readily regenerated, and the easy recycling of both photo-catalyst makes the process very promising, using sunlight as the irradiation contributes to the competitiveness of the process. This research probably provides new potential routes for Cd-based catalysts synthesis in the photocatalytic oxidative desulfurization domain. Where, the desulfurization process is simple and readily used without precipitation, separation, calcination steps, and the easy separation is favored by the immiscibility of the photo liquid catalyst with the oil feedstock. Therefore, this work is promising and can be applied in the development of the diesel desulfurization process.

\section{CRediT authorship contribution statement}

Asmaa S. Morshedy: Conceptualization, Methodology, Data curation, Software, Visualization, Writing - original draft, Writing review \& editing. Sahar M. Tawfik: Supervision, Writing - review \& editing. Karam M. Hashem: Data curation, Software, Visualization. Dina M. Abd El-Aty: Data curation, Software. Ahmed A. Galhoum: Validation, Writing - review \& editing. Mohsen S. Mostafa: Validation. Eric Guibal: Methodology, Writing - original draft, Software, Visualization, Supervision, Writing - review \& editing.

\section{Declaration of competing interest}

The authors declare that they have no known competing financial interests or personal relationships that could have appeared to influence the work reported in this paper.

\section{Acknowledgments}

This work was financially supported by the Egyptian Petroleum Research Institute (EPRI), Egypt. E.G., thanks to the support from Institut Français d'Egypte (French Government) for supporting the collaboration with Nuclear Materials Authority (NMA, Egypt).

\section{Appendix A. Supplementary data}

Supplementary data to this article can be found online at https://doi.org/10.1016/j.jclepro.2020.123629.

\section{References}

Abro, R., Abdeltawab, A.A., Al-Deyab, S.S., Yu, G., Qazi, A.B., Gao, S., Chen, X., 2014. A review of extractive desulfurization of fuel oils using ionic liquids. RSC Adv. 4 (67), 35302-35317.

Achary, S.R., Agouram, S., Sánchez-Royo, J.F., Martínez-Tomás, M.C., MuñozSanjosé, V., 2014. One-step growth of isolated CdO nanoparticles on r-sapphire substrates by using the spray pyrolysis methodology. RSC Adv. 4 (44), 23137-23144.

Adar, F., 2016. Introduction to interpretation of Raman spectra using database searching and functional group detection and identification. Spectrosc. Spectr. Anal. 31 (7), 16-23.

Al-Shahrani, F., Xiao, T., Llewellyn, S.A., Barri, S., Jiang, Z., Shi, H., Martinie, G., Green, M.L., 2007. Desulfurization of diesel via the $\mathrm{H}_{2} \mathrm{O}_{2}$ oxidation of aromatic sulfides to sulfones using a tungstate catalyst. Appl. Catal., B 73 (3-4), 311-316.

Albada, H.B., Soulimani, F., Weckhuysen, B.M., Liskamp, R.M.J., 2007. Scaffolded amino acids as a close structural mimic of type-3 copper binding sites. Chem. Commun. (46), 4895-4897.

Ali, M.F., Al-Malki, A., El-Ali, B., Martinie, G., Siddiqui, M.N., 2006. Deep desulphurization of gasoline and diesel fuels using non-hydrogen consuming techniques. Fuel 85 (10-11), 1354-1363.

Amjed, N., Bhatti, I.A., Nazir, A., Iqbal, M., 2017. Microwave-assisted desulfurization of coal by photo-catalytic oxidation treatment. Energy Sources, Part A 39 (10), 
1043-1049.

Anandhan, K., Harish, S., Thilak Kumar, R., 2019. Effect of morphology on the formation of CdO nanostructures for Antibacterial and Hemolytic studies. Appl. Surf. Sci. 489, 262-268.

Ashoka, S., Chithaiah, P., Chandrappa, G.T., 2010. Studies on the synthesis of $\mathrm{CdCO}_{3}$ nanowires and porous CdO powder. Mater. Lett. 64 (2), 173-176.

Barmala, M., Behnood, M., Omidkhah, M.R., 2018. Photo oxidation of DBT using carbon nanotube titania composite as visible light active photo catalyst. J. Cent. South Univ. 25 (7), 1642-1650.

Bedre, M., Deshpande, R., Salimath, B., Abbaraju, V., 2012. Preparation and characterization of polyaniline- $\mathrm{CO}_{3} \mathrm{O}_{4}$ nanocomposites via interfacial polymerization. Am. J. Mater. Sci. 12 (3), 39-43.

Chen, S., Zhao, C., Liu, Q., Zang, M., Liu, C., Zhang, Y., 2018. Thermophilic biodesulfurization and its application in oil desulfurization. Appl. Microbiol. Biotechnol. 102 (21), 9089-9103.

Chong, S.Y., Wang, T.T., Cheng, L.C., Lv, H.Y., Ji, M., 2019. Metal-organic framework MIL-101- $\mathrm{NH}_{2}$-supported acetate-based butylimidazolium ionic liquid as a highly efficient heterogeneous catalyst for the synthesis of 3-Aryl-2oxazolidinones. Langmuir 35 (2), 495-503.

Cuba, M., Qamhieh, N., Saleh, N., Kumar, R.T.A., Mousa, H.A., Mahmoud, S.T., 2018. Synthesis and photoluminescence enhancement of pure CdO: annealing effect study. J. Lumin. 198, 289-295.

de Leon, J.N.D., Kumar, C.R., Antunez-Garcia, J., Fuentes-Moyado, S., 2019. Recent insights in transition metal sulfide hydrodesulfurization catalysts for the production of ultra low sulfur diesel: a short review. Catalysts 9 (1).

Dharaskar, S., Sillanpaa, M., Tadi, K.K., 2018. Sulfur extraction from liquid fuels using trihexyl(tetradecyl)phosphonium tetrafluoroborate: as promising solvent. Environ. Sci. Pollut. Res. 25 (17), 17156-17167.

Dharaskar, S., Wasewar, K., Varma, M., Shende, D., Chang, K.Y., 2014. Environmentally benign process for removal of sulfur from liquid fuel using imidazolium based ionic liquids. Res. J. Chem. Environ. 18 (2), 94-99.

Dharaskar, S.A., Wasewar, K.L., Varma, M.N., Shende, D.Z., Yoo, C.K., 2013. Deep removal of sulfur from model liquid fuels using 1-Butyl-3-Methylimidazolium Chloride. In: Mehta, U. (Ed.), Chemical, Civil and Mechanical Engineering Tracks of 3rd Nirma University International Conference on Engineering, pp. $416-422$.

Dizaji, A.K., Mokhtarani, B., Mortaheb, H.R. 2019. Deep and fast oxidative desulfurization of fuels using graphene oxide-based phosphotungstic acid catalysts. Fuel 236, 717-729.

Dong, W., Zhu, C., 2003. Optical properties of surface-modified CdO nanoparticles. Opt. Mater. 22 (3), 227-233.

Duarte, F.A., Mello, P.d.A., Bizzi, C.A., Nunes, M.A.G., Moreira, E.M., Alencar, M.S., Motta, H.N., Dressler, V.L., Flores, E.M.M., 2011. Sulfur removal from hydrotreated petroleum fractions using ultrasound-assisted oxidative desulfurization process. Fuel 90 (6), 2158-2164.

Etemadi, N., Sepahy, A.A., Mohebali, G., Yazdian, F., Omidi, M., 2018. Enhancement of bio-desulfurization capability of a newly isolated thermophilic bacterium using starch/iron nanoparticles in a controlled system. Int. J. Biol. Macromol. 120, 1801-1809.

Gao, H., Zeng, S., Liu, X., Nie, Y., Zhang, X., Zhang, S., 2015. Extractive desulfurization of fuel using N-butylpyridinium-based ionic liquids. RSC Adv. 5 (38), 30234-30238.

Gao, J., Zhu, S., Dai, Y., Xiong, C., Li, C., Yang, W., Jiang, X., 2018. Performance and mechanism for extractive desulfurization of fuel oil using modified polyethylene glycol. Fuel 233, 704-713.

Gao, L.G., Li, H.X., Song, X.L., Li, W.L., Ma, X.R., 2019. Degradation of benzothiophene in diesel oil by LaZnAl layered double hydroxide: photocatalytic performance and mechanism. Pet. Sci. 16 (1), 173-179.

García-Gutiérrez, J.L., Fuentes, G.A., Hernández-Terán, M.E., Garcia, P., MurrietaGuevara, F., Jiménez-Cruz, F., 2008. Ultra-deep oxidative desulfurization of diesel fuel by the $\mathrm{Mo} / \mathrm{Al}_{2} \mathrm{O}_{3}-\mathrm{H}_{2} \mathrm{O}_{2}$ system: the effect of system parameters on catalytic activity. Appl. Catal., A 334 (1-2), 366-373.

Ghoshal, T., Kar, S., De, S.K., 2009. Morphology controlled solvothermal synthesis of $\mathrm{Cd}(\mathrm{OH})_{2}$ and $\mathrm{CdO}$ micro/nanocrystals on Cd foil. Appl. Surf. Sci. 255 (18), 8091-8097.

Grado-Caffaro, M.A., Grado-Caffaro, M., 2008. A quantitative discussion on bandgap energy and carrier density of $\mathrm{CdO}$ in terms of temperature and oxygen partial pressure. Phys. Lett. 372 (27-28), 4858-4860.

Gulino, A., Compagnini, G., Scalisi, A.A., 2003. Large third-order nonlinear optical properties of cadmium oxide thin films. Chem. Mater. 15 (17), 3332-3336.

Gutierrez, A., Atilhan, M., Aparicio, S., 2018. Theoretical study of oil desulfuration by ammonium-based deep eutectic solvents. Energy Fuels 32 (7), 7497-7507.

Hassan, S.I., El-Din, O.I.S., Tawfik, S.M., El-Aty, D.M.A., 2013. Solvent extraction of oxidized diesel fuel: phase equilibrium. Fuel Process. Technol. 106, 127-132.

Hatada, K., Terawaki, Y., Kitayama, T., Kamachi, M., Tamaki, M., 1981. Studies on the radical polymerization of vinyl acetate in benzene, chlorobenzene and ethyl acetate by 1H NMR spectroscopy. Polym. Bull. 4 (8), 451-458.

Hong, H.J., Kim, B.G., Ryu, J., Park, I.S., Chung, K.S., Lee, S.M., Lee, J.B., Jeong, H.S., Kim, H., Ryu, T., 2018. Preparation of highly stable zeolite-alginate foam composite for strontium(Sr-90) removal from seawater and evaluation of $\mathrm{Sr}$ adsorption performance. J. Environ. Manag. 205, 192-200.

Hu, S., Wang, A., Li, X., Wang, Y., Löwe, H., 2010. Hydrothermal synthesis of ionic liquid [bmim] $\mathrm{OH}$-modified $\mathrm{TiO}_{2}$ nanoparticles with enhanced photocatalytic activity under visible light. Chem. Asian J. 5 (5), 1171-1177.

Hu, Z., Lu, S., Huang, X., Li, J., Duan, Y., Yan, L., Yao, Y., Liao, X., 2018. Molybdenum anchored on $\mathrm{NH}_{2}$-modified spherical $\mathrm{SiO}_{2}$ : a highly efficient and stable catalyst for oxidative desulfurization of fuel oil. Appl. Organomet. Chem. 32 (11).

Ito, K., Bernstein, H.J., 1956. The vibrational spectra of the formate, acetate, and oxalate ions. Can. J. Chem. 34 (2), 170-178.

Jatav, S., Srivastava, V.C., 2019. $\mathrm{Ce} / \mathrm{Al}_{2} \mathrm{O}_{3}$ as an efficient catalyst for oxidative desulfurization of liquid fuel. Petrol. Sci. Technol. 37 (6), 633-640.

Javadli, R., de Klerk, A., 2012. Desulfurization of heavy oil. Appl. Petrochem. Res. 1 (1), 3-19.

Tha, D. Mubarak, N.M., Haider, M.B., Kumar, R., Balathanigaimani, M.S., Sahu, J.N. 2019. Adsorptive removal of dibenzothiophene from diesel fuel using microwave synthesized carbon nanomaterials. Fuel 244, 132-139.

Jiang, B., Sun, Z., Zhang, L., Sun, Y., Zhang, H., Yang, H., 2018. Synthesis of a hypercrosslinked, ionic, mesoporous polymer monolith and its application in deep oxidative desulfurization. J. Appl. Polym. Sci. 135 (21).

Jiang, W., Zhu, K., Li, H., Zhu, L., Hua, M., Xiao, J., Wang, C., Yang, Z., Chen, G., Zhu, W. Li, H., Dai, S., 2020. Synergistic effect of dual Brønsted acidic deep eutectic solvents for oxidative desulfurization of diesel fuel. Chem. Eng. J. 394, 124831.

Jing, L., Wang, M., Li, X., Xiao, R., Zhao, Y., Zhang, Y., Yan, Y.-M., Wu, Q., Sun, K., 2015 Covalently functionalized $\mathrm{TiO}_{2}$ with ionic liquid: a high-performance catalyst for photoelectrochemical water oxidation. Appl. Catal., B 166, 270-276.

Juliao, D., Mirante, F., Ribeiro, S.O., Gomes, A.C., Valenca, R., Ribeiro, J.C., Pillinger, M., de Castro, B., Goncalves, I.S., Balula, S.S., 2019. Deep oxidative desulfurization of diesel fuels using homogeneous and SBA-15-supported peroxophosphotungstate catalysts. Fuel 241, 616-624.

Kalathur, A.S., 2005. Cathodic Electrodeposition of Cadmium Oxide, Zinc Oxide and Mixed Cadmium Oxide-Zinc Oxide Thin Films, Materials Science and Engineering. University of Texas at Arlington, Arlington (TX), USA.

Kamide, K., Okajima, K., 1981. Determination of distribution of O-acetyl group in trihydric alcohol units of cellulose acetate by carbon-13 nuclear magnetic resonance analysis. Polym. J. 13 (2), 127-133.

Kaviyarasu, K., Manikandan, E., Kennedy, J., Jayachandran, M., 2014. Quantum confinement and photoluminescence of well-aligned CdO nanofibers by a solvothermal route. Mater. Lett. 120, 243-245.

Keynejad, K., Nikazar, M., Dabir, B., 2017. Diesel desulfurization using a UVphotocatalytic process. Petrol. Sci. Technol. 35 (9), 813-819.

Khallaf, H., Chen, C.-T., Chang, L.-B., Lupan, O., Dutta, A., Heinrich, H., Shenouda, A., Chow, L., 2011. Investigation of chemical bath deposition of CdO thin films using three different complexing agents. Appl. Surf. Sci. 257 (22), 9237-9242.

Ko, C.H., Park, J.G., Han, S.-S., Park, J.-H., Cho, S.-H., 2007. Adsorptive desulfurization of diesel using metallic nickel supported on SBA-15 as adsorbent. Stud. Surf. Sci. Catal. 881-884.

Kowsaka, K., Okajima, K., Kamide, K., 1986. Further study on the distribution of substituent group in cellulose acetate by $13 \mathrm{C}\{1 \mathrm{H}\} N M R$ analysis: assignment of carbonyl carbon peaks. Polym. J. 18 (11), 843-849.

Krisnamurthy, N., 1962. Raman spectrum of crystalline cadmium acetate dihydrate Proc. Indian Acad. Sci. 61 (2), 113-118.

Landau, M.V., Herskowitz, M., Agnihotri, R., Kegerreis, J.E., 2008. Ultradeep Adsorption - desulfurization of gasoline with $\mathrm{Ni} / \mathrm{Al}-\mathrm{SiO}_{2}$ material catalytically facilitated by ethanol. Ind. Eng. Chem. 47 (18), 6904-6916.

Liu, J., Li, X.-M., He, J., Wang, L.-Y., Lei, J.-D., 2018. Combining the photocatalysis and

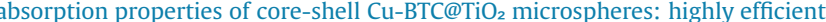
desulfurization of thiophenic compounds from fuel. Materials 11 (11)

Lv, H., Guang, J., Liu, Y., Tang, H., Zhang, P., Lu, Y., Wang, J., 2015. Synthesis of ionic liquid-modified $\mathrm{BiPO}_{4}$ microspheres with hierarchical flower-like architectures and enhanced photocatalytic activity. RSC Adv. 5 (122), 100625-100632.

Ma, X., Sun, L., Song, C., 2002. A new approach to deep desulfurization of gasoline diesel fuel and jet fuel by selective adsorption for ultra-clean fuels and for fue cell applications. Catal. Today 77 (1), 107-116.

Magdalane, C.M., Kaviyarasu, K., Vijaya, J.J., Siddhardha, B., Jeyaraj, B., 2016. Photocatalytic activity of binary metal oxide nanocomposites of $\mathrm{CeO}_{2} / \mathrm{CdO}$ nanospheres: investigation of optical and antimicrobial activity. J. Photochem. Photobiol., B 163, 77-86.

Majumder, S., Mendhe, A.C., Kim, D., Sankapal, B.R., 2019. CdO nanonecklace: effect of air annealing on performance of photo electrochemical cell. J. Alloys Compd. $788,75-82$.

Manjunatha, C., Nagabhushana, B.M., Nagabhushana, H., Chakradhar, R.P.S., 2012 Transformation of hydrothermally derived nanowire cluster intermediates into $\mathrm{CdSiO}_{3}$ nanobelts. J. Mater. Chem. 22 (42), 22392-22397.

Mazaheritehrani, M., Asghari, J., Orimi, R.L. Pahlavan, S., 2010. Microwave-assisted synthesis of nano-sized cadmium oxide as a new and highly efficient catalys for solvent free acylation of amines and alcohols. Asian J. Chem. 22 (4) 2554-2564.

Miao, G., Huang, D., Ren, X., Li, X., Li, Z., Xiao, J., 2016. Visible-light induced photocatalytic oxidative desulfurization using $\mathrm{BiVO}_{4} / \mathrm{C}_{3} \mathrm{~N}_{4} @ \mathrm{SiO}_{2}$ with air/cumene hydroperoxide under ambient conditions. Appl. Catal., B 192, 72-79.

Miao, G., Ye, F., Wu, L., Ren, X., Xiao, J., Li, Z., Wang, H., 2015. Selective adsorption of thiophenic compounds from fuel over $\mathrm{TiO}_{2} / \mathrm{SiO}_{2}$ under UV-irradiation. J. Hazard Mater. 300, 426-432.

More, N.S., Gogate, P.R. 2019. Intensified approach for desulfurization of simulated fuel containing thiophene based on ultrasonic flow cell and oxidizing agents. Ultrason. Sonochem. 51, 58-68.

Morshedy, A.S., El Naggar, A.M.A., Tawfik, S.M., El-Din, O.I.S., Hassan, S.I., Hashem, A.I., 2016. Photoassisted desulfurization induced by visible-light irradiation for the production of ultra-low sulfur diesel fuel using nanoparticles of CdO. J. Phys. Chem. B 120 (46), 26350-26362. 
Nezamzadeh-Ejhieh, A., Banan, Z., 2011. A comparison between the efficiency of CdS nanoparticles/zeolite $\mathrm{A}$ and $\mathrm{CdO} /$ zeolite $\mathrm{A}$ as catalysts in photodecolorization of crystal violet. Desalination 279 (1-3), 146-151.

Otsuki, S., Nonaka, T., Takashima, N., Qian, W., Ishihara, A., Imai, T., Kabe, T., 2000 Oxidative desulfurization of light gas oil and vacuum gas oil by oxidation and solvent extraction. Energy Fuels 14 (6), 1232-1239.

Patil, K.C., Chandrashekhar, G.V., George, M.V., Rao, C.N.R., 1968. Infrared spectra and thermal decompositions of metal acetates and dicarboxylates. Can. J. Chem. 46 (2), 257-265.

Pelaez, M., Falaras, P., Likodimos, V., O'Shea, K., de la Cruz, A.A., Dunlop, P.S.M. Byrne, J.A., Dionysiou, D.D., 2016. Use of selected scavengers for the determination of $\mathrm{NF}_{-} \mathrm{TiO}_{2}$ reactive oxygen species during the degradation of microcystin-LR under visible light irradiation. J. Mol. Catal. Chem. 425, 183-189.

Pi, M., Wu, T., Zhang, D., Chen, S., Wang, S., 2016. Facile preparation of semimetallic $\mathrm{WP}_{2}$ as a novel photocatalyst with high photoactivity. RSC Adv. 6 (19), $15724-15730$.

Popovic, Z.V., Stanisic, G., Stojanovic, D., Kostic, R., 1991. Infrared and Raman spectra of CdO. Phys. Status Solidi B 165 (2), K109-K112.

Priebe, A., Pucci, A., Akermann, W., Grabhorn, H., Otto, A., 2006. Staggered ethane changes to eclipsed conformation upon adsorption. J. Raman Spectrosc. 37 (12) 1398-1402.

Ranjbar, Z.R., Morsali, A., 2011. Ultrasound assisted syntheses of a nano-structured two-dimensional mixed-ligand cadmium(II) coordination polymer and direct thermolyses for the preparation of cadmium(II) oxide nanoparticles. Polyhedron 30 (6), 929-934.

Reddy, C.V., Babu, B., Shim, J., 2018. Synthesis, optical properties and efficient photocatalytic activity of $\mathrm{CdO} / \mathrm{ZnO}$ hybrid nanocomposite. J. Phys. Chem. Solid. $112,20-28$.

Ren, Z., Wei, L., Zhou, Z., Zhang, F., Liu, W., 2018. Extractive desulfurization of model oil with protic ionic liquids. Energy Fuels 32 (9), 9172-9181.

Sae-Ma, N., Praserthdam, P., Panpranot, J., Chaemchuen, S., Dokjamp, S., Suriye, K., Rempel, G.L., 2010. Color improvment of C-9 hydrocarbon resin by hydrogenation over $2 \% \mathrm{Pd} /$ gamma-allumina catalyst: effect of degree of aromatic rings hydrogenation. J. Appl. Polym. Sci. 117 (5), 2862-2869.

Seo, D.J., 2004. Structural and optical properties of CdO films deposited by spray pyrolysis. J. Kor. Phys. Soc. 45 (6), 1575.

Sher Shah, M.S.A., Kim, W.-J., Park, J., Rhee, D.K. Jang, I.-H., Park, N.-G., Lee, J.Y., Yoo, P.J., 2014. Highly efficient and recyclable nanocomplexed photocatalysts of $\mathrm{AgBr} / \mathrm{N}$-doped and amine-functionalized reduced graphene oxide. ACS Appl. Mater. Interfaces 6 (23), 20819-20827.

Shiraishi, Y., Tachibana, K., Hirai, T., Komasawa, I., 2002. Desulfurization and denitrogenation process for light oils based on chemical oxidation followed by Liquid-Liquid extraction. Ind. Eng. Chem. 41 (17), 4362-4375.

Sutton, C.C.R. Franks, G.V. da Silva, G., 2015. Modeling the antisymmetric and symmetric stretching vibrational modes of aqueous carboxylate anions. Spectrochim. Acta, Part A 134, 535-542.

Tadjarodi, A., Imani, M., 2011a. A novel nanostructure of cadmium oxide synthesized by mechanochemical method. Mater. Res. Bull. 46 (11), 1949-1954.

Tadjarodi, A., Imani, M., 2011b. Synthesis and characterization of CdO nanocrystalline structure by mechanochemical method. Mater. Lett. 65 (6), 1025-1027.

Thomas, P., Abraham, K.E., 2015. Excitation wavelength dependent visible photoluminescence of CdO nanomorphotypes. J. Lumin. 158, 422-427.

Torki, F., Faghihian, H., 2017. Photocatalytic activity of NiS, NiO and coupled $\mathrm{NiS}-\mathrm{NiO}$ for degradation of pharmaceutical pollutant cephalexin under visible light. RSC Adv. 7 (86), 54651-54661.

Tumula, V.R., Bondwal, S., Bisht, P., Pendem, C., Kumar, J., 2012. Oxidation of sulfides to sulfones with hydrogen peroxide in the presence of acetic acid and Amberlyst 15. React. Kinet. Mech. Catal. 107 (2), 449-466.

Ullah, L., Zhao, G., Hedin, N., Ding, X., Zhang, S., Yao, X., Nie, Y., Zhang, Y., 2019. Highly efficient adsorption of benzothiophene from model fuel on a metalorganic framework modified with dodeca-tungstophosphoric acid. Chem. Eng. J. 362, 30-40.

Vadgama, V.S., Vyas, R.P., Jogiya, B.V., Joshi, M.J., 2017. Synthesis and characterization of CdO nano particles by the sol-gel method. In: Kuberkar, D.G., Shah, N.A. (Eds.), Functional Oxides and Nanomaterials.

Varghese, N., Panchakarla, L.S., Hanapi, M., Govindaraj, A., Rao, C.N.R., 2007. Solvothermal synthesis of nanorods of $\mathrm{ZnO}, \mathrm{N}$-doped $\mathrm{ZnO}$ and CdO. Mater. Res. Bull. 42 (12), 2117-2124.

Vinodkumar, R, Lethy, KJ. Arunkumar, P.R, Krishnan, R.R., Pillai, N.V, Pillai, V.P.M. Philip, R., 2010. Effect of cadmium oxide incorporation on the microstructural and optical properties of pulsed laser deposited nanostructured zinc oxide thin films. Mater. Chem. Phys. 121 (3), 406-413.

Wang, C., Zhu, W., Xu, Y., Xu, H., Zhang, M., Chao, Y., Yin, S., Li, H., Wang, J., 2014b. Preparation of $\mathrm{TiO}_{2} / \mathrm{g}-\mathrm{C}_{3} \mathrm{~N}_{4}$ composites and their application in photocatalytic oxidative desulfurization. Ceram. Int. 40 (8), 11627-11635.

Wang, H.M., You, C.F., 2016. Photocatalytic removal of low concentration $\mathrm{SO}_{2}$ by titanium dioxide. Chem. Eng. J. 292, 199-206.

Wang, J., Zhang, L., Sun, Y., Jiang, B., Chen, Y., Gao, X., Yang, H., 2018. Deep catalytic oxidative desulfurization of fuels by novel Lewis acidic ionic liquids. Fuel Process. Technol. 177, 81-88.

Wang, X., Zhang, W., Wu, L., Ye, F., Xiao, J., Li, Z., 2014a. One-pot photocatalysisassisted adsorptive desulfurization of diesel over doped- $\mathrm{TiO}_{2}$ under ambient conditions. RSC Adv, 4 (100), 56567-56570.

Yakuphanoglu, F., 2010. Nanocluster n-CdO thin film by sol-gel for solar cell applications. Appl. Surf. Sci. 257 (5), 1413-1419.

Zeng, X., Xiao, X., Chen, J., Wang, H., 2019. Electron-hole interactions in cholinephosphotungstic acid boosting molecular oxygen activation for fuel desulfurization. Appl. Catal., B 248, 573-586.

Zeng, X.Y., Xiao, X.Y., Li, Y., Chen, J.Y., Wang, H.L., 2017. Deep desulfurization of liquid fuels with molecular oxygen through graphene photocatalytic oxidation. Appl. Catal., B 209, 98-109.

Zhang, L., Wang, J., Sun, Y., Jiang, B., Yang, H., 2017b. Deep oxidative desulfurization of fuels by superbase-derived Lewis acidic ionic liquids. Chem. Eng. J. 328, 445-453.

Zhang, W., Li, X., Wang, H., Song, Y., Zhang, S., Li, C., 2017a. Deep desulfurization of model oil by photocatalytic air oxidation and adsorption using $\mathrm{Ti}_{(1-\mathrm{x})} \mathrm{M}_{(\mathrm{x})} \mathrm{O}_{2}$ ( $\mathrm{M}=\mathrm{Zr}$, Ce). Kor. J. Chem. Eng. 34 (12), 3132-3141.

Zhang, Y.C., Wang, G.L., 2008. Solvothermal synthesis of CdO hollow nanostructures from $\mathrm{CdO}_{2}$ nanoparticles. Mater. Lett. 62 (4), 673-675.

Zhao, K., Cheng, Y., Liu, H., Yang, C., Qiu, L., Zeng, G., He, H., 2015. Extractive desulfurization of dibenzothiophene by a mixed extractant of $\mathrm{N}, \mathrm{N}-$ dimethylacetamide, N,N-dimethylformamide and tetramethylene sulfone: optimization by Box-Behnken design. RSC Adv. 5 (81), 66013-66023.

Zhao, M., Han, P.F., Lu, X.P., 2018. Ultrasound assisted photocatalytic oxidative desulfurization of model diesel fuel. Petrol. Sci. Technol. 36 (1), 29-33.

Zhu, W., Wang, C., Li, H., Wu, P., Xun, S., Jiang, W., Chen, Z., Zhao, Z., Li, H., 2015. Onepot extraction combined with metal-free photochemical aerobic oxidative desulfurization in deep eutectic solvent. Green Chem. 17 (4), 2464-2472.

Zhu, W., Xu, Y., Li, H., Dai, B., Xu, H., Wang, C., Chao, Y., Liu, H., 2014. Photocatalytic oxidative desulfurization of dibenzothiophene catalyzed by amorphous $\mathrm{TiO}_{2}$ in ionic liquid. Kor. J. Chem. Eng. 31 (2), 211-217.

Ziabari, A.A., Ghodsi, F.E., 2011. Optoelectronic studies of sol-gel derived nanostructured CdO-ZnO composite films. J. Alloys Compd. 509 (35), 8748-8755. 